\title{
Mantle Echoes Associated with Deep Convection: Observations and Numerical Simulations
}

\author{
Roger M. Wakimoto, Hanne V. Murphey, and Robert G. Fovell \\ Department of Atmospheric Sciences, University of California, Los Angeles, Los Angeles, California \\ Wen-Chau LeE \\ National Center for Atmospheric Research, * Boulder, Colorado
}

(Manuscript received 21 July 2003, in final form 18 December 2003)

\begin{abstract}
Finescale radar observations of intense thermals/starting plumes, during the early stages of precipitation formation, were collected by an airborne Doppler radar on two separate days. The radar data were recorded as the aircraft flew underneath the developing echoes. Mantle echoes (echoes that often appear as an inverted U shape) were observed on both days. Striking in one of the scans was the resemblance of the echo to a mushroom cloud resulting from a nuclear explosion. Numerical simulations using a two-dimensional cloud-resolving model were run to augment the interpretation of the observations. One of the important conclusions was the proposed modification to the default bulk microphysical scheme used in the model. The default scheme yields "a rush to precipitation" leading to the early establishment of large precipitation contents, which is not supported by the observations. Suggested modifications to the scheme are presented.
\end{abstract}

\section{Introduction}

Radar has played a prominent role in revealing the internal structure of convective storms. In addition, the echo patterns and Doppler velocity wind syntheses have frequently been compared with numerical simulations in order to 1) verify whether the simulations generated realistic results, and 2) provide a more complete dynamical explanation of the observations (e.g., Klemp et al. 1981; Rotunno et al. 1988). While these studies have led to significant advances in our understanding of convection, they have been primarily focused on the mature stage of convection rather than on the initiating phase.

There have been numerous laboratory (e.g., Scorer 1957; Turner 1973, 165-206) and numerical simulations (e.g., Ogura 1962; Lilly 1964) of thermals or buoyant plumes. It is surprising to note, however, that detailed observations in the atmosphere have been limited to shallow thermals within the convective boundary layer (CBL) (e.g., Lenschow 1970; Hall et al. 1975) and cumulus clouds (e.g., Malkus 1954; Telford and Warner

\footnotetext{
* The National Center for Atmospheric Research is sponsored by the National Science Foundation.

Corresponding author address: Dr. Roger M. Wakimoto, Department of Atmospheric Sciences, UCLA, 405 Hilgard Avenue, Los Angeles, CA 90095-1565.

E-mail: roger@atmos.ucla.edu
}

1962; Knight and Miller 1998). Indeed, to the authors' knowledge, there have been no detailed radar observations of the vertical structure of deep convection during the early stages of development.

The field phase of a large multiagency and international program called the International $\mathrm{H}_{2} \mathrm{O}$ Project (IHOP) was operated during the spring and summer of 2002 in Texas, Oklahoma, and Kansas. The overarching goal of IHOP was to improve the characterization of the four-dimensional distribution of water vapor and its application to improve the understanding and prediction of convection (Weckwerth et al. 2004). One of the primary scientific objectives of the program was to document the formation and evolution of boundaries within the CBL to better understand the processes that initiate deep, moist convection. These boundaries are frequently observed as enhanced thin or fine lines with a sensitive Doppler radar that is able to detect echoes within the clear air (Wilson and Schreiber 1986).

One of the platforms deployed during IHOP was the Electra Doppler Radar (ELDORA; Hildebrand et al. 1994), an airborne Doppler radar that has the ability to sample convective storms with high spatial resolution and also the sensitivity to detect clear-air returns (e.g., see, Wakimoto et al. 1996). Unique vertical cross sections of the early stages of deep convection were recorded by ELDORA as it flew beneath developing echoes on 2 days during the experiment. On both days 
ELDORA observed mantle echoes (Atlas 1959; Knight and Miller 1993) that extended throughout the entire depth of the troposphere. The term "mantle" describes the configuration of the echo that often appears as an inverted $U$ shape in a vertical cross section and corresponds to the outer boundaries of the cumulus clouds. Mantle echoes associated with deep convection have not been previously documented in the literature. The observations documented in this paper present an important opportunity to test the ability of a numerical cloud model to replicate the echo structure during the earliest stages of a deep convective cloud. Cloud models resolve individual convective elements while parameterizing microphysical processes, usually in a bulk fashion. In particular, the performance of a commonly employed microphysical parameterization scheme can be evaluated.

Section 2 describes ELDORA and the flight patterns flown during IHOP. The meteorological setting and the vertical cross sections of the mantle echoes on 2 days (19 and 12 June) during the experiment are presented in sections 3 and 4, respectively. Section 5 presents results from a series of numerical simulations, and a summary and discussion are presented in section 6 .

\section{ELDORA and the flight patterns}

ELDORA is a 3-cm airborne Doppler radar equipped with two antennae that scan in a direction normal to the fuselage of a P-3 aircraft. The antennae scan slightly fore and aft of the normal by $\sim 18.5^{\circ}$ so that the sweeps are cross sections that are nearly vertical [i.e., nearly range height indicators (RHIs)] but are actually conical. Wakimoto et al. (1996), among others, have shown that this scan type can reveal the finescale vertical structure of convective storms.

The convection initiation missions during IHOP required ELDORA to fly at low levels between 500 and $650 \mathrm{~m}$ above ground level (AGL; hereafter, all heights are AGL). The mission scientists endeavored to direct the aircraft within a few kilometers and parallel to a radar-detected thin line identified by the operations center. The shape of the flight pattern was an elongated box with alongfront legs nominally $75-80 \mathrm{~km}$ long. The objective was to attain the highest spatial resolution of the kinematic structure of the boundary and to note any significant alongfrontal variability. Since convection frequently initiates along these convergence boundaries (Wilson and Schreiber 1986), the P-3 was in a prime location to fly underneath the developing echoes while ELDORA recorded unique views of its vertical structure. Fortunately, this scenario occurred on two separate days during IHOP-12 and 19 June.

\section{19 June 2002}

A dryline formed ahead of a cold front on 19 June in northwest Kansas. There are northerly winds north- west of the frontal boundary at 2100 UTC (hereafter, all times are UTC) shown in the surface analysis superimposed onto a visible satellite image (Fig. 1a). A narrow, dry tongue of air separating the cold front and dryline is apparent by the warm temperature and low dewpoint temperature reported at the surface station located northwest of the storm in the figure. The cloud line apparent in the satellite image delineates the position of the dryline. Strong southerly flow is shown east of the dryline, and intense convection has already initiated along the dryline near the Colorado-Kansas border.

ELDORA departed from Oklahoma City, Oklahoma, and was able to quickly locate the dryline based on the in situ data collected at flight level. Ten flight legs were flown by the aircraft over a 3 -h period. One of the box patterns executed by the aircraft around the dryline is shown in Fig. 1a. Convection continued to initiate along the entire line as far north as Nebraska by 2300 (Fig. 1b). The P-3 terminated its low-level flight along the boundary at the latter time owing to the intensity of the storms. The line of thunderstorms was accompanied by numerous reports of hail and high winds in northwest Kansas. Four tornadoes and three tornadoes rated F0 and $\mathrm{F} 1$, respectively, were reported by the National Weather Service.

The vertical structure of the winds, virtual potential temperature, and mixing ratio across the boundaries were revealed by data recorded by a series of dropsondes deployed from a Learjet (Fig. 2; the locations of the dropsondes are shown in Fig. 3). Three distinct air masses can be identified in Fig. 2. The post-cold front air was characterized by cool, moist conditions and persistent northerly flow up to a depth of $750 \mathrm{mb}$. Cool and moist conditions associated with southerly flow were also noted east of the dryline. The air mass between the two boundaries is warm, relatively dry, and accompanied by westerly winds. The black dots denote the positions and flight-level data recorded by the Naval Research Laboratory (NRL) P-3 as it flew through the plane of the cross section while flying the box pattern around the dryline. The location where convection first initiates is denoted by the upward bulge of mixing ratio and virtual potential temperature isopleths near the dryline (Fig. 2).

The flight track of the aircraft centered at 2100 is superimposed onto the Weather Surveillance Radar1988 Doppler (WSR-88D) radar reflectivity image recorded at Goodland, Kansas (Fig. 3). The dryline can be identified in the clear-air return as a thin line of radar reflectivity (Wilson and Schreiber 1986). A fine line denoting the position of the surface cold front, positioned just east of the WSR-88D site based on analysis shown in Fig. 2, was not apparent in the radar data.

Radar reflectivity and Doppler velocity data recorded by ELDORA were separated by $\sim 600 \mathrm{~m}$ in the alongtrack direction and $1.5^{\circ}$ in the direction of the sweeps. Navigation corrections were implemented using the 

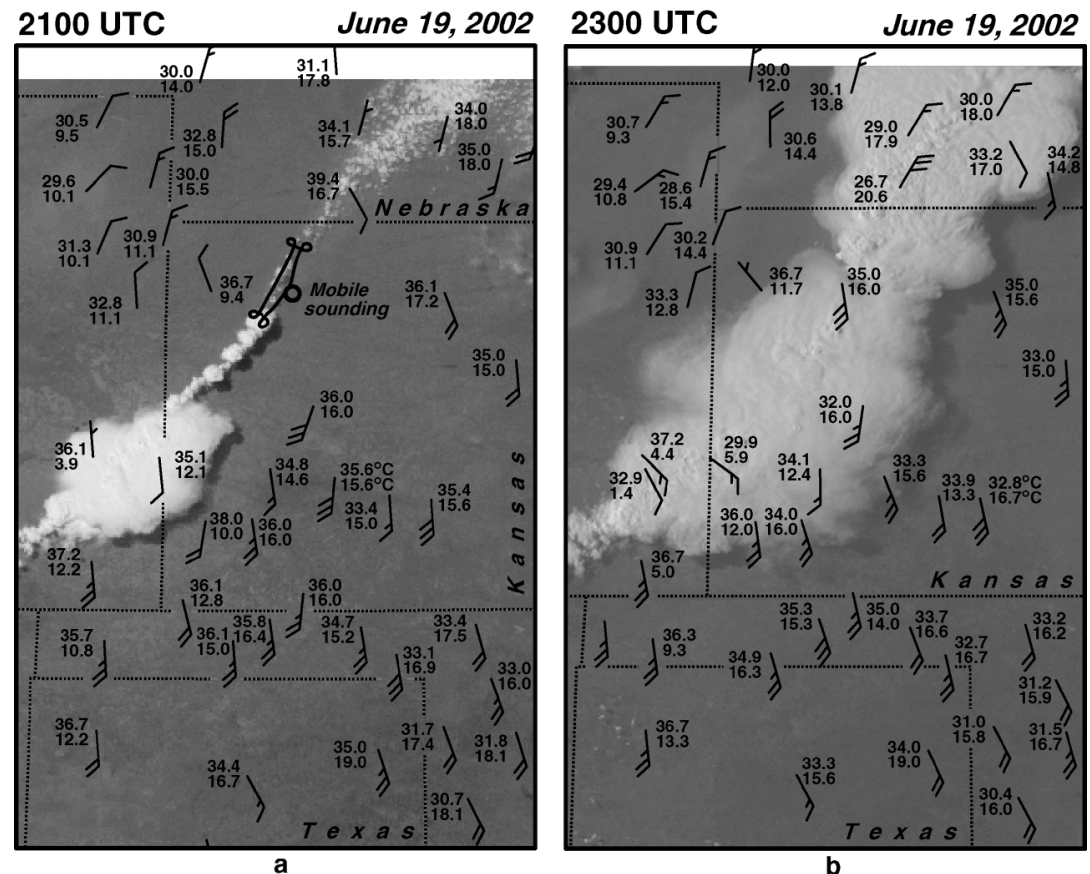

FIG. 1. Surface analysis at (a) 2100 and (b) 2300 UTC 19 Jun superimposed onto visible satellite images. Temperature, dewpoint temperature, and wind speed and direction are plotted The black line in (a) represents the flight track of the P-3. The black circle represents the location of a sounding that is shown in Fig. 14. Wind vectors are plotted with the full barb and half barb representing 5 and $2.5 \mathrm{~m} \mathrm{~s}^{-1}$, respectively.

June 19, 2002

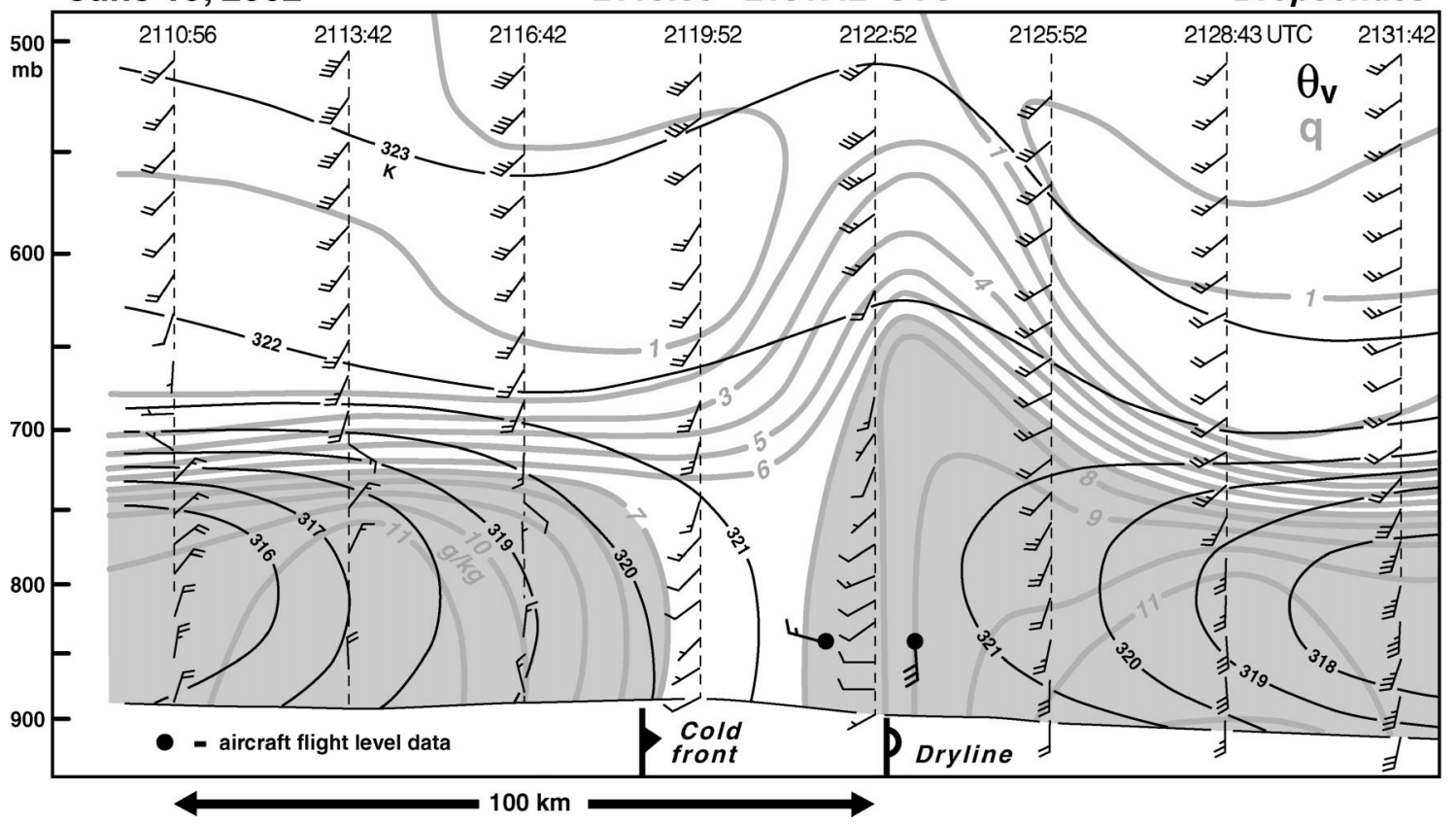

FIG. 2. Northwest-southeast cross section of winds, virtual potential temperature (black lines), and mixing ratio (gray lines) across a cold front and dryline on 19 Jun 2002 based on a series of dropsondes deployed from an aircraft. Dropsonde locations are shown in Fig. 3. Black dots represent the positions of the penetrations through the cross section by the NRL P-3. Mixing ratio values greater than $7 \mathrm{~g} \mathrm{~kg}^{-1}$ are shaded gray. Wind vector notation is the same as in Fig. 1. 


\section{UTC}

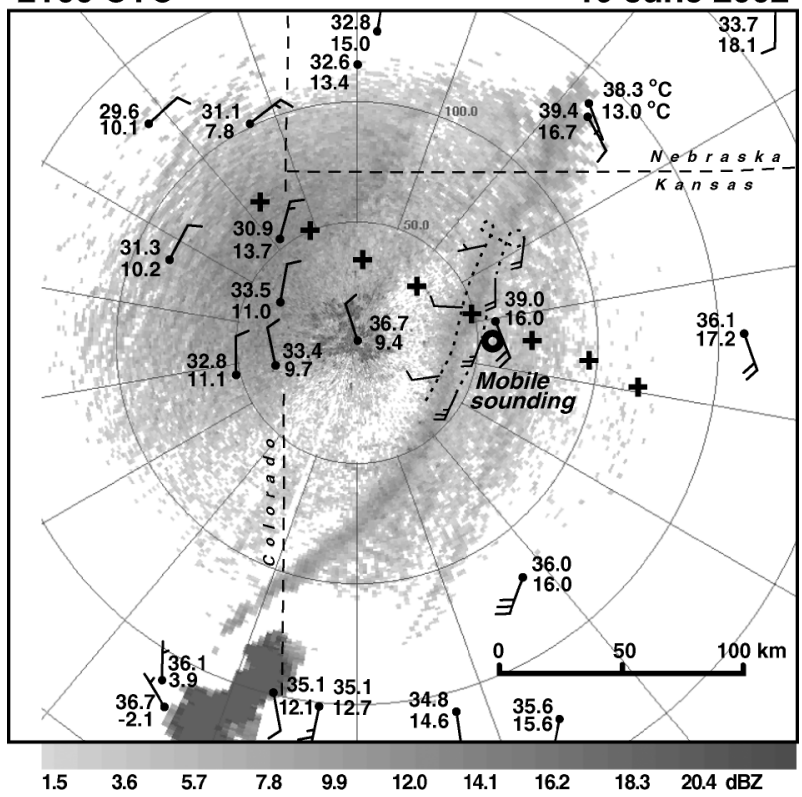

FIG. 3. Surface analysis at 2100 UTC 19 Jun superimposed onto a WSR-88D radar reflectivity image recorded at $0.5^{\circ}$ elevation angle from Goodland, KS. Temperature, dewpoint temperature, and wind speed and direction are plotted. The black circle represents the location of a sounding that is shown in Fig. 14. The dotted line represents the flight track of the P-3. The times of the flight legs are 2048-2059 and 2105-2117 UTC. The flight-level winds $(\sim 600 \mathrm{~m}$ AGL) are plotted. The radar reflectivity scale is shown on the bottom of the figure. The black crosses denote the position of the dropsondes shown in Fig. 2. Wind vector notation is the same as in Fig. 1.

techniques proposed by Testud et al. (1995) and Bosart et al. (2002). In addition, the data were transformed from aircraft-relative to ground-relative coordinates using the scheme suggested by Lee et al. (1994). In the analysis domain, the maximum vertical sampling was approximately $262 \mathrm{~m}$ at a distance of $10 \mathrm{~km}$ from the aircraft. As a result, the reflectivity and Doppler velocity data were interpolated onto a Cartesian grid with horizontal and vertical grid spacings of 600 and $300 \mathrm{~m}$, respectively, using Reorder software (Oye et al. 1995). The lowest grid level was located at $400 \mathrm{~m}$. The dryline was quasi stationary during the observational period so the individual radar scans were not time-space adjusted. A Cressman filter (1959) was used in the interpolation process with a radius of influence of 600 and $300 \mathrm{~m}$ in the horizontal and vertical, respectively. The data were synthesized within Custom Editing and Display of Reduced Information in Cartesian space (CEDRIC) software (Mohr et al. 1986). A three-step Leise filter (Leise 1982) was applied to the synthesis that removes wavelengths of $4.8 \mathrm{~km}$ or less.

One of the wind syntheses (2137:00-2149:22) at 400 $\mathrm{m}$ is shown in Fig. 4. The fine line associated with the dryline is apparent and is collocated with a confluence line in the wind field. As will be shown in section 5, the environment east of the dryline was unstable, with
2137:00 - 2149:22 UTC $400 \mathrm{~m} \mathrm{AGL}$

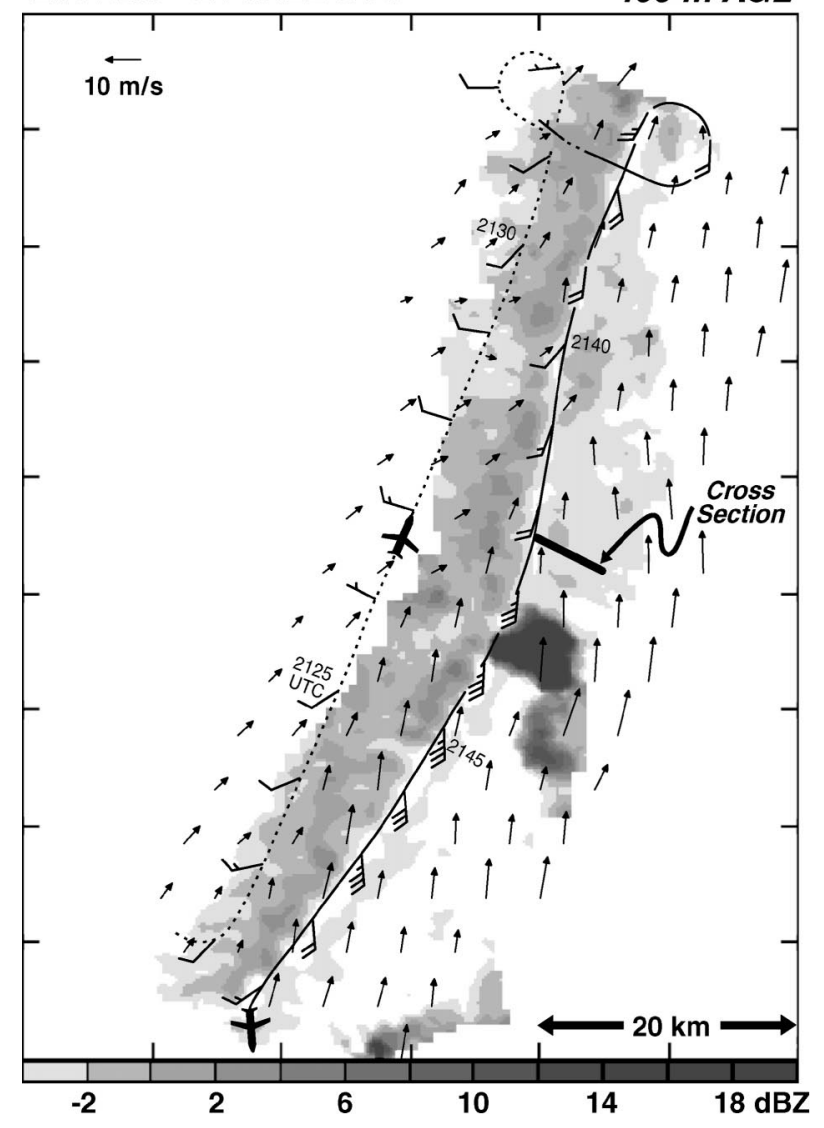

FIG. 4. Radar reflectivity and Doppler wind syntheses at $400 \mathrm{~m}$ AGL from 2137:00 to 2149:22 UTC 19 Jun. The flight-level track and ground-relative winds are plotted. The wind synthesis is based on the portion of the flight track drawn as a black line. The wind synthesis from the previous pass (dotted line) is not shown. The thick, black line represents the location of the ELDORA tail radar scan presented in Fig. 6. Flight level of the aircraft is $600 \mathrm{~m}$ AGL. Wind vector notation is the same as in Fig. 1.

large convective available potential energy (CAPE) values. A first echo forming above the thin line was detected in a vertical scan by ELDORA at 2052 (Fig. 5). The peak reflectivities within the echo were $\sim-8 \mathrm{dBZ}$ at a height of $\sim 7 \mathrm{~km}$. The reflectivity image suggests that the depth of the dryline-associated thin line was $\sim 2.5 \mathrm{~km}$. The single-Doppler velocity pattern in the bottom panel of Fig. 5 suggests low-level convergence within the dryline, as highlighted by the black arrows. The velocity structure within the echo aloft is consistent with the classical schematic diagrams of a rising thermal (e.g., Scorer 1957) and has a $22 \mathrm{~m} \mathrm{~s}^{-1}$ updraft at its center along with descending flow $\left(5 \mathrm{~m} \mathrm{~s}^{-1}\right)$ at its periphery (indicated by the red and green colors in the image, respectively).

The mantle echo on this day was observed about 50 min later, during the synthesis shown in Fig. 4. The echo pattern shown in Fig. 6 consists of a "ram's horn" structure surrounding a pronounced weak-echo vault 


\section{2:21 UTC}

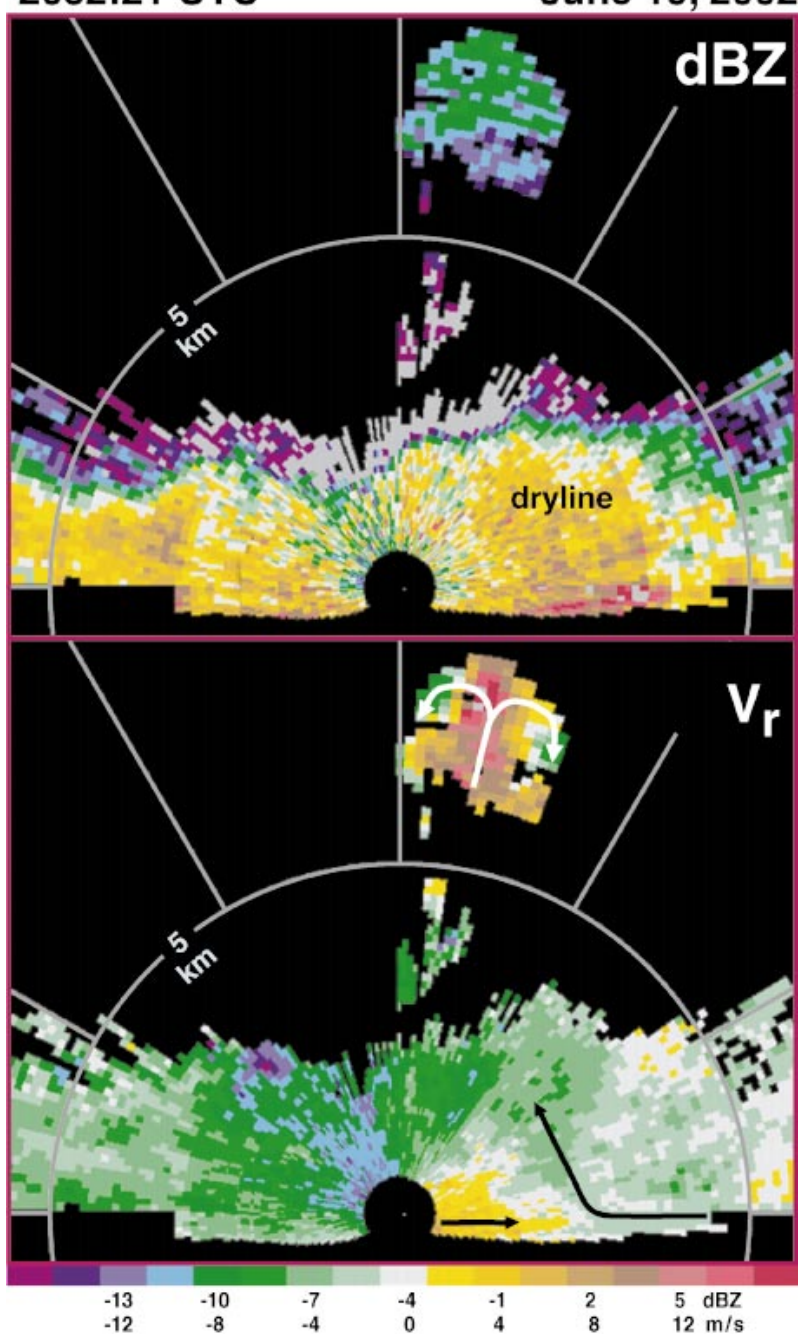

FIG. 5. ELDORA tail radar scan through a first echo on 19 Jun at 2052:21 UTC: (top) radar reflectivity and (bottom) single-Doppler velocity. Black arrows on the velocity image approximate the flow. Gray lines are the range rings and angles from the aircraft.

(the vault structure was verified by examining adjacent radar scans). The maximum reflectivities barely exceed $17 \mathrm{dBZ}$ even though the echo top extends to $13 \mathrm{~km}$. The maximum updraft speeds estimated from the Doppler velocities are $>40 \mathrm{~m} \mathrm{~s}^{-1}$. It should be noted that this represents a lower-bound estimate since the radar may not be sampling the full component of the velocity. No correction for terminal fall speed needs to be applied to the vertical velocities in the present case since the echoes are weak (N. B., it is possible that these small reflectivities might be due to sparse but large scatterers). While the velocity pattern within the mantle echo is more complex than was shown in Fig. 5, there remains an overall pattern of strong ascent within the weak-echo region with downdrafts along its flanks. The pockets of negative Doppler velocities surrounded by positive velocities at the echo top may indicate the presence of
2142:21 UTC

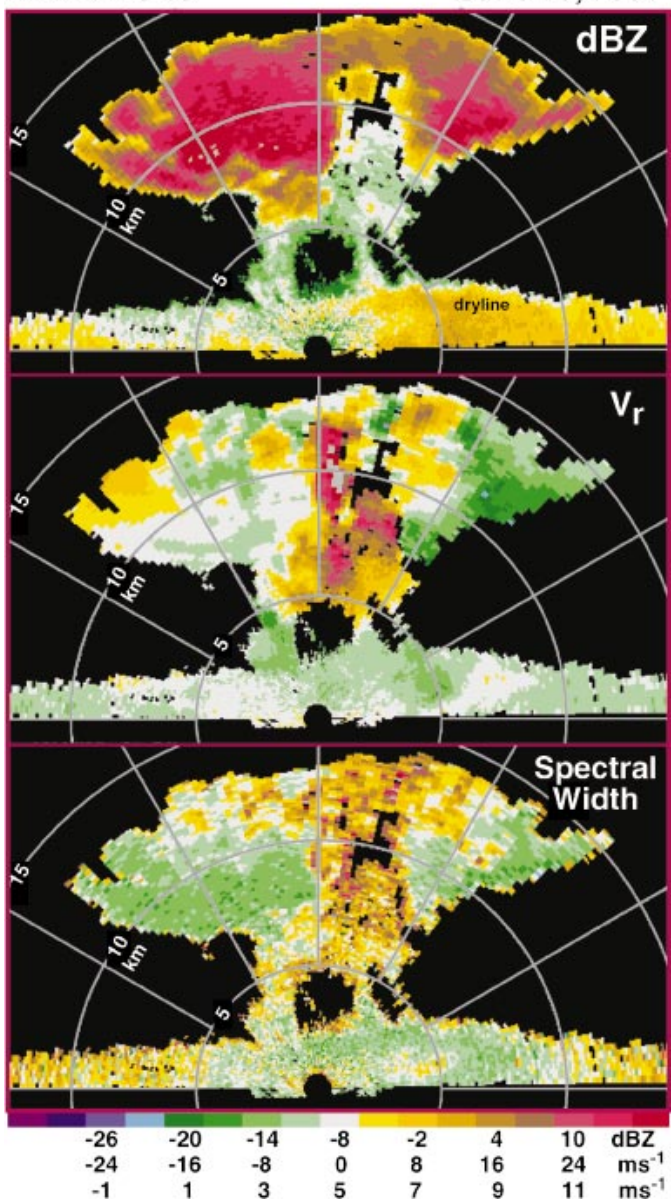

FIG. 6. ELDORA tail radar scan through a developing storm on 2142:21 UTC 19 Jun: (top) reflectivity, (middle) single-Doppler velocity, and (bottom) spectral width. Location of the cross section is shown in Fig. 4. Gray lines are the range rings and angles from the aircraft.

gravity waves and/or the collapse of overshooting cloud tops.

The width of the Doppler power spectrum is often used as a proxy for turbulence. Large values of spectral width are found both within the updraft and near the echo top, suggesting both areas are turbulent, while relatively small values occur elsewhere within the echo. Increased turbulence at cloud top is not surprising in light of the accompanying single-Doppler velocity image suggesting small, and closely spaced, regions of ascent and descent. It is not clear that the turbulence is large within the weak echo, however. The large spectral widths there could represent noise since the very small reflectivity values are near the minimum detectable signal.

It is intriguing to speculate on the cause for the observed echo "streamers" that are apparent between 2 and $5 \mathrm{~km}$ extending from the boundary layer into the mantle echo aloft (Fig. 6). Part of the return may be due to Bragg scattering (i.e., small-scale spatial varia- 

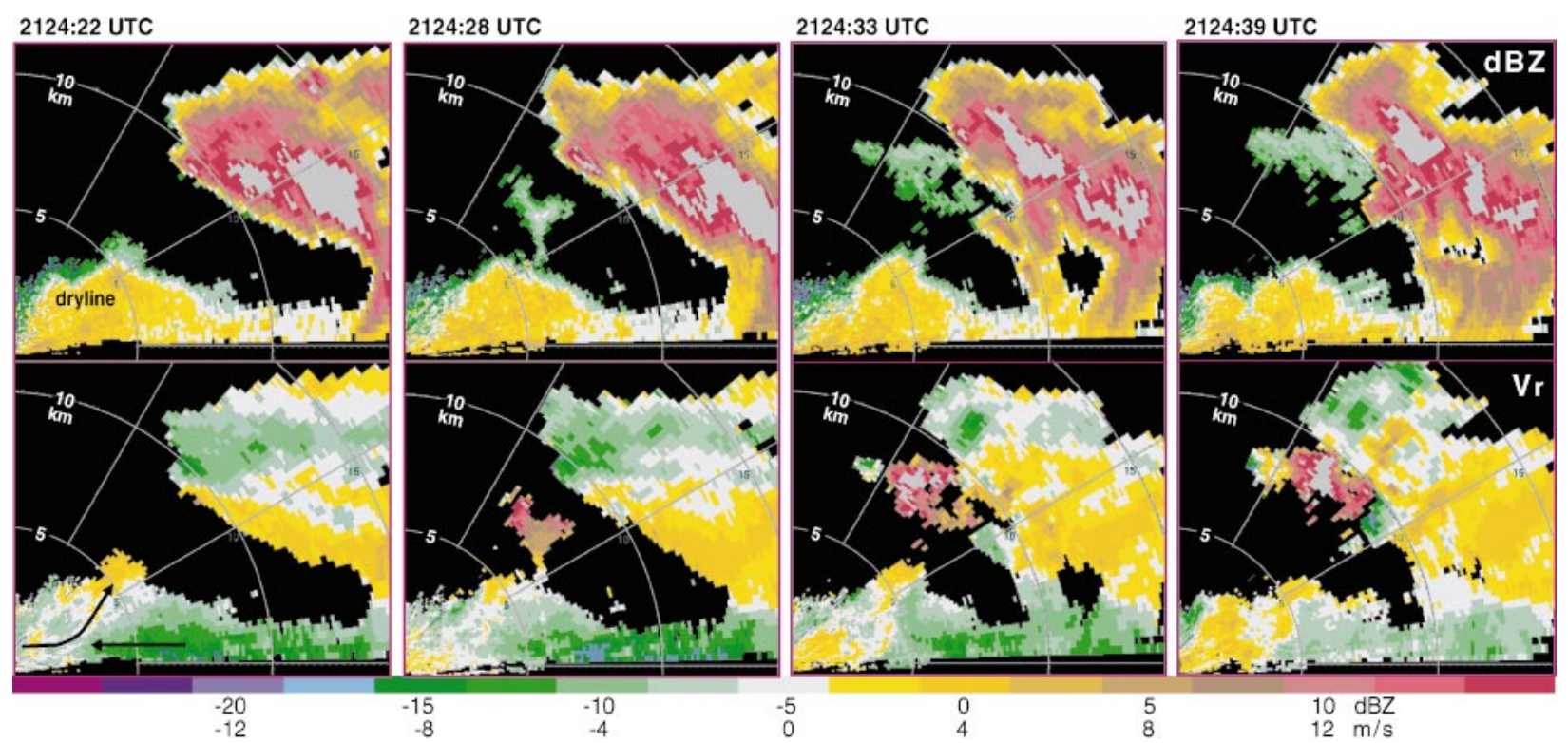

FIG. 7. Four consecutive ELDORA tail radar scans (2124:22, 2124:28, 2124:33, and 2124:39 UTC) on 19 Jun 2002 through a thin line and developing storm: (top) radar reflectivity and (bottom) single-Doppler velocity. Gray lines are the range rings and angles from the aircraft.

tions in refractive index typically less than one-half the radar wavelength; see Doviak and Zrnic 1993). Knight and Miller (1993), however, suggest that Bragg scattering can be effectively discounted for a $3-\mathrm{cm}$ radar if the reflectivity values are greater than $-10 \mathrm{dBZ}$. They suggest that in these instances, the echo return should be backscatter from hydrometeors or, on rare occasions, insects. A significant portion of the echoes within the streamers in Fig. 6 are associated with reflectivity greater than $-10 \mathrm{dBZ}$. It appears that insects are likely the major contributor to the backscatter radar signal since the origin of the streamers appears to be too low for hydrometeors to have had the time to grow to a radardetectable size.

Two additional examples provide compelling evidence that insects that originated from the thin line are being swept up and into strong updrafts on this day. Four consecutive scans by the ELDORA tail radar are shown in Fig. 7. The sequence depicts an echo streamer with its roots attached to the thin line at 2124:22 and "feeds" into the developing storm at a height of $\sim 8$ $\mathrm{km}$. Note the large positive Doppler velocities within the streamer in the last three panels. Another striking example is shown in Fig. 8. A tilted, plumelike echo can be identified emanating from the thin line associated with the dryline. The plume fans out and the echo weakens as it extends into the weak-echo vault of the storm. The single-Doppler velocities reveal that the plume is located above a convergence zone associated with the dryline and is embedded within the main storm updraft.

\section{12 June 2002}

The surface analysis on 12 June was complicated by the existence of multiple boundaries and air masses (Fig. 9a). The strong, southerly flow in western Oklahoma is both warm and moist. A remnant outflow boundary from a mesoscale convective system (seen as a cloud line in Fig. 9a) separated the warm, moist air from cooler, southeasterly flow in eastern Oklahoma. A southwestto-northeast-oriented cloud line extending through the Texas panhandle appeared to mark a weak dryline with warmer and drier air reported at several stations to the west of the boundary. The dashed line in the figure represents the position of a trough associated with a prominent wind shift. The center of a low pressure (hereafter, referred to as the low) was identifiable in the isobar analysis (not shown) and the wind field in the eastern Oklahoma panhandle. The dryline intersected the outflow boundary forming a "triple point" east of the low. Convection initiated along most of the dryline, and a severe storm developed near the triple point (note the anvil east of the low center along the KansasOklahoma border in Fig. 9b). This storm produced golfball-size hail, maximum outflow wind speeds exceeding $30 \mathrm{~m} \mathrm{~s}^{-1}$, flash flooding, and at least one tornado.

There were several flight patterns that could have been flown on this day owing to the number of boundaries present. The P-3, based on guidance from the operations center, flew east-west legs that were parallel to, and on both sides of, the outflow boundary (see Fig. 9a). Surface stations and the P-3 flight track superimposed onto a radar reflectivity image at 2100 from the WSR-88D located at Dodge City, Kansas, is shown in Fig. 10. The cyclonic flow around the low can be seen

${ }^{1}$ The term "triple point" is often used to denote the intersection point of any three distinct air masses (e.g., Reed and Albright 1997). 


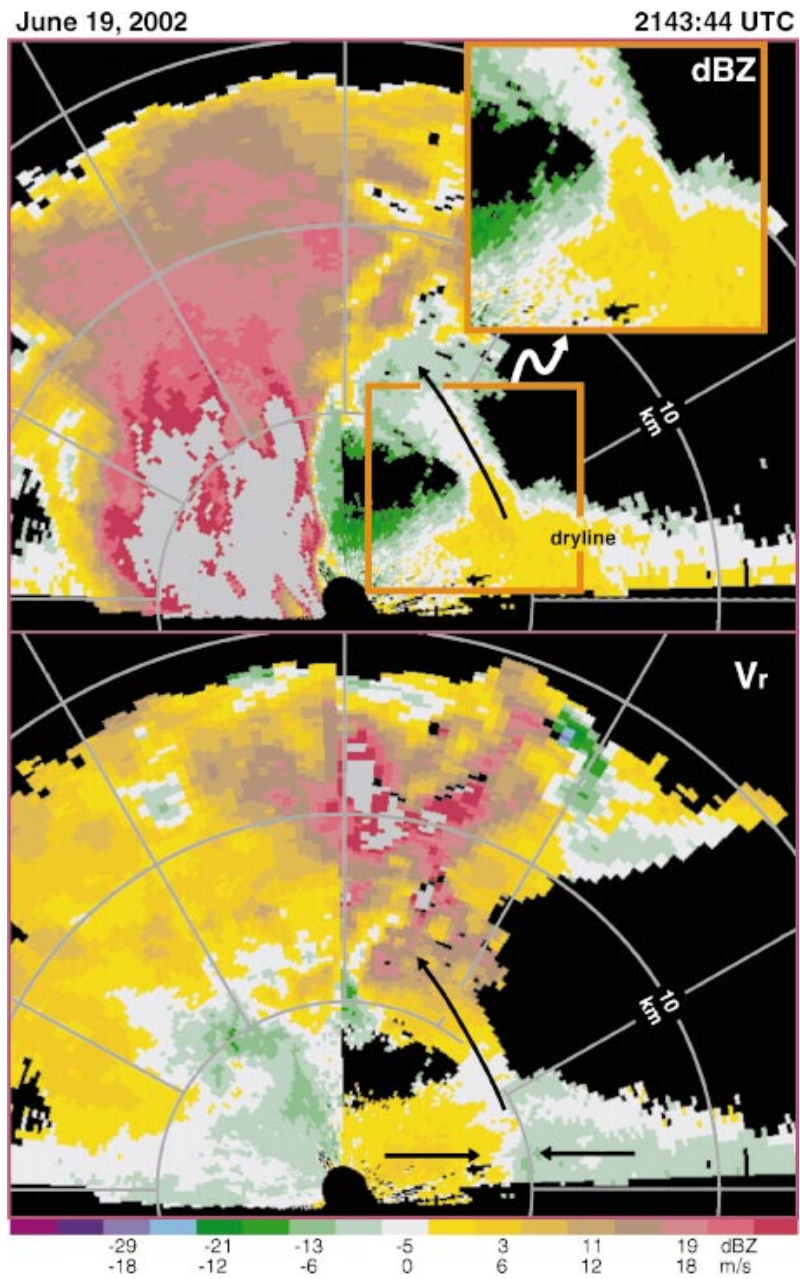

FIG. 8. ELDORA tail radar scan through a thin line and storm on 2143:44 UTC 19 Jun 2002: (top) radar reflectivity and (bottom) single-Doppler velocity. The thin line enclosed by the orange box is enlarged in the top panel. Gray lines are the range rings and angles from the aircraft.

in the figure. Thin lines associated with the outflow boundary and the dryline intersect at a triple point east of the low. The flight track encompasses the triple point and penetrates the low.

The scanning parameters for ELDORA on this day were the same as the mission flown on 19 June. Accordingly, the data methodology for the Doppler wind syntheses is the same. The boundary was quasi stationary so the individual radar scans were not time-space adjusted. The synthesis at $400 \mathrm{~m}$ for the flight leg from 2102:02 to 2113:01 is shown in Fig. 11.

The triple point formed by the intersection of the dryline and the outflow boundary is clearly defined in the reflectivity field. The position of the low is based on the circulation center that can be identified in the Doppler wind field and is located at a discontinuity in the east-west thin line. The line is displaced to the north and to the south, east, and west of the low, respectively.
This thin line also has significant alongfrontal variability throughout its entire length. There are numerous bands of enhanced echo within the line that are oriented in a northwest-to-southeast direction. These bands could also be seen in the WSR-88D scan shown in Fig. 10, and their orientation is perpendicular to the low-level wind direction. The mechanism that produced the bandlike structure and the reason for the lack of a kinematic discontinuity across some of these boundaries is currently under investigation.

The severe storm that was noted in Fig. 9b was sampled by ELDORA during its initiation phase near the triple point. The radar detected a mantle echo but a weak-echo vault was not in evidence (Fig. 12). Echo tops and maximum reflectivities were $\sim 11 \mathrm{~km}$ and greater than $39 \mathrm{dBZ}$, respectively. The resemblance of the echo to a mushroom cloud resulting from a nuclear explosion is remarkable. The echo possesses a mushroom cap near the tropopause with a narrow trunklike structure below suggesting a starting plume structure (i.e., a jetlike bouyant jet commencing with a well-defined, thermal-like cap). There are filaments or limblike echo structures that extend downward from the trunk between 4 and $7 \mathrm{~km}$. One of these features, directly above the aircraft, is located near the rotational couplet highlighted by the arrow on the Doppler velocity image, suggesting that there is strong shear vorticity across the periphery of the trunk.

The maximum positive Doppler velocities are greater than $30 \mathrm{~m} \mathrm{~s}^{-1}$ but are not located in the center of the plume where the peak updrafts would be expected to occur. Therefore, it is possible that the viewing angle of the antenna is not sampling the full component of the updraft in the present case. The spectral widths suggest that the upper half of the echo, including the mantle, is associated with large turbulence. Interestingly, the plume below $5 \mathrm{~km}$ is accompanied by much lower values of spectral width, suggesting more laminar flow there. This may indicate that the plume was undiluted until it reached $5 \mathrm{~km}$. The large values of spectral width along the sides of the mantle echo are probably noise due to the weak signal in those locations; however, owing to strong shear along the flanks of the plume, turbulence cannot be ruled out.

The low-level echo that makes up the trunk in Fig. 12 most likely represents scattering from insects originating in the boundary layer and not Bragg scattering, based on discussions presented in the previous section. At higher levels, the echo returns are from hydrometeor scattering. Surprisingly, there is no obvious discontinuity in the radar reflectivity pattern shown in the figure that highlights where the transition between hydrometeors and insects might be located. It is interesting to speculate that the insects that are rapidly swept aloft into the developing storm by the strong updraft act as nuclei for the developing hydrometeors. 


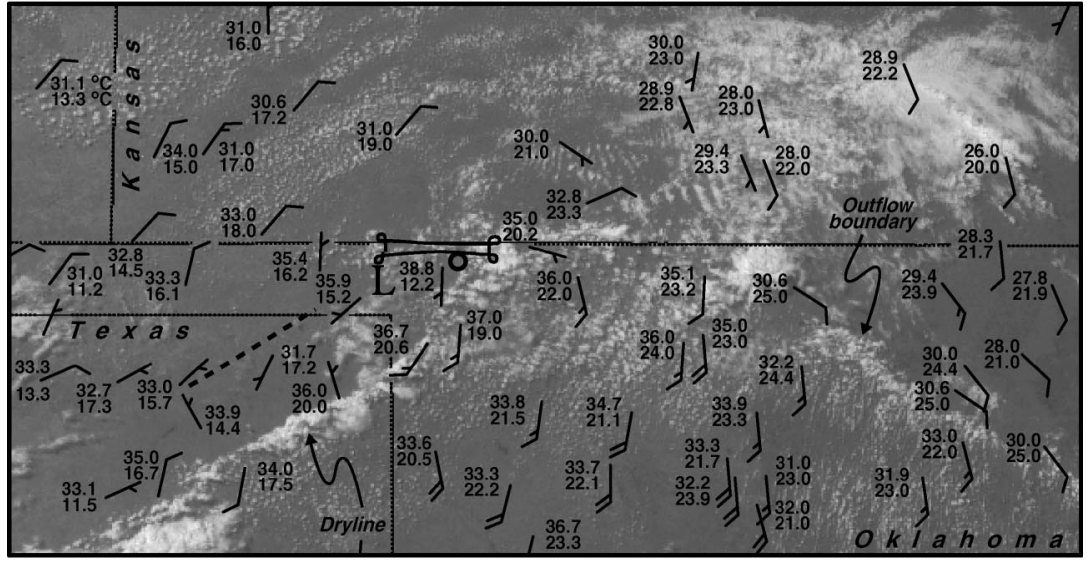

a

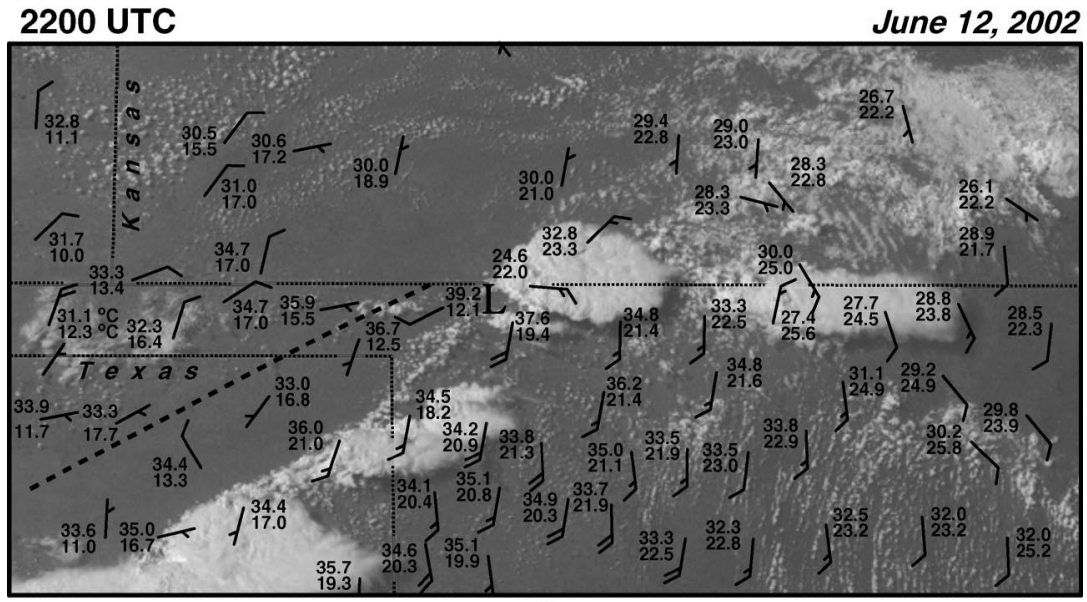

b

FIG. 9. Surface analysis at (a) 2100 and (b) 2200 UTC 12 Jun superimposed onto visible satellite images. Temperature, dewpoint temperature, and wind speed and direction are plotted. The black line in (a) represents the flight track of the P-3. The black circle represents the location of a dropsonde that is shown in Fig. 15. The dashed line indicates the position of a windshift line. Wind vector notation is the same as in Fig. 1.

\section{Numerical simulations}

\section{a. Overview of the simulations}

The 19 June radar cross section (Fig. 6) exhibited a ram's horn structure surrounding a prominent weak-echo vault that extended well above the $10-\mathrm{km}$ level. In contrast, 12 June's echo (Fig. 12) was more slablike with no echo vault in evidence. Figure 13 shows simulation results inspired by these two cases $\sim 18$ min after initialization, presented in subdomains sized and shaped to facilitate comparison with the observations. The 19 June model storm echo also concentrates the larger reflectivities into a ram's horn-like arrangement surrounding a weak-echo vault containing a narrow and strong updraft. The core vertical velocities exceed about $50 \mathrm{~m} \mathrm{~s}^{-1}$ at the time shown; this compares well to the observations. Similar to the observations, the 12 June echo is more slablike, located at a lower altitude and perched atop a somewhat wider and considerably less intense updraft.
These simulations were made with a two-dimensional version of the Advanced Regional Prediction System (ARPS) model, with a customized microphysical parameterization and initializations designed to reproduce the most salient features of the two mantle echo cases. ARPS (Xue et al. 2003) is a compressible, cloud-resolving model with parameterized microphysics. The model domain was $250 \mathrm{~km}$ wide and $21 \mathrm{~km}$ deep, with uniform grid spacings of 500 and $100 \mathrm{~m}$ in the horizontal and vertical directions, respectively. The grid arrangement employed is deemed appropriate given the phenomenon being simulated and the resolution of the observations. As will be described later, convection was initiated with thermals of varying sizes, shapes, and humidities, designed to explore the effect of thermal ascent rate on the results. Reflectivities were estimated using the method of Smith (1984).

The default ARPS microphysics is based on the Lin et al. (1983) Lin-Farley-Orville (LFO) scheme, a very 
2100 UTC

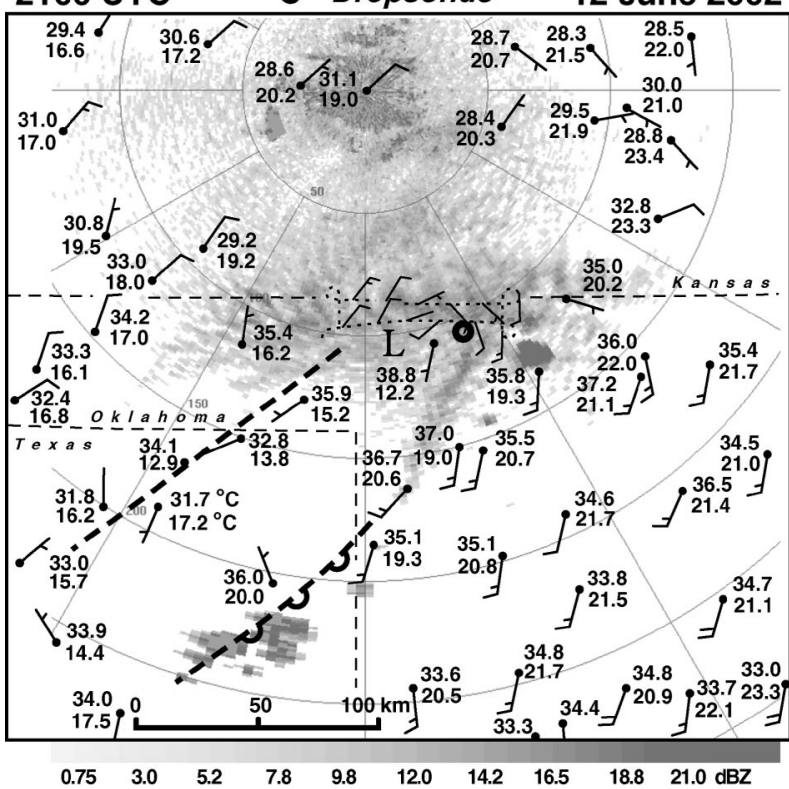

FIG. 10. Surface analysis at 2100 UTC 12 Jun superimposed onto a WSR-88D radar reflectivity image recorded at $0.5^{\circ}$ elevation angle from Dodge City. Temperature, dewpoint temperature, and wind speed and direction are plotted. The black circle represents the location of a dropsonde that is shown in Fig. 15. The dotted line represents the flight track of the P-3. The flight-level winds $(\sim 600 \mathrm{~m}$ AGL) are plotted. Wind vector notation is the same as in Fig. 1. commonly used bulk parameterization that recognizes five types of condensed water: free-floating cloud droplets and ice crystals and precipitation in the form of raindrops, lower density ice (snowflakes), and higher density ice (hail). The precipitation categories are presumed to have Marshall-Palmer-type exponential size distributions (Marshall and Palmer 1948) upon which fall speeds and collection rates are based. Such distributions are defined by their intercept and slope parameters; in the LFO scheme, the intercept $N_{0 x}$ is held fixed while the slope $\lambda_{x}$ is made inversely proportional to the total mass of precipitation type $x$. Alternative schemes in which the intercept is free to vary (e.g., Cotton et al. 1986; Reisner et al. 1998) have also been proposed. The microphysical scheme itself consists of a complex set of conversion equations.

Overall, the LFO scheme has proved an adequate and relatively efficient choice for cloud dynamical studies, especially those focusing on mature, well-organized storms, and thus represents a reasonable starting point for our simulations. In this situation, however, the default ARPS microphysical setup yields a "rush to precipitation" resulting in the early establishment of large precipitation contents and very bright echoes, results clearly at variance with the observations on these 2 days. The simulations shown in Fig. 13 were made with a customized version of LFO specifically designed to slow this evolution, without stopping it, permitting the model

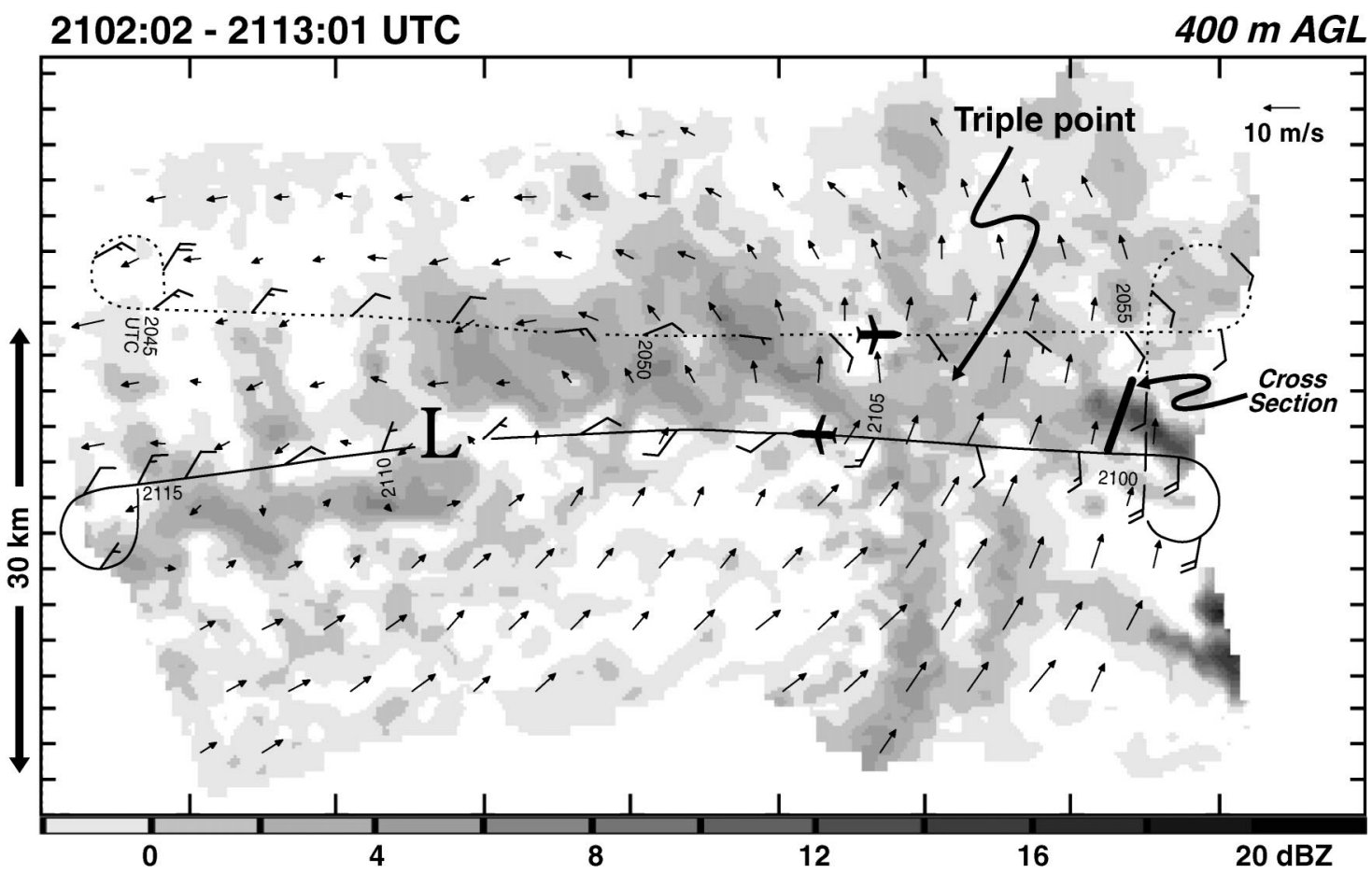

FIG. 11. Radar reflectivity and ground-relative Doppler wind syntheses at $400 \mathrm{~m}$ AGL from 2102:02 to 2113:01 UTC 12 Jun. The flight-level track and winds are plotted. The wind synthesis presented is based on the portion of the flight track drawn as a black line. The wind synthesis from the previous pass (dotted line) is not shown. The thick, black line represents the location of the ELDORA tail radar scan presented in Fig. 12. Wind vector notation is the same as in Fig. 1. 


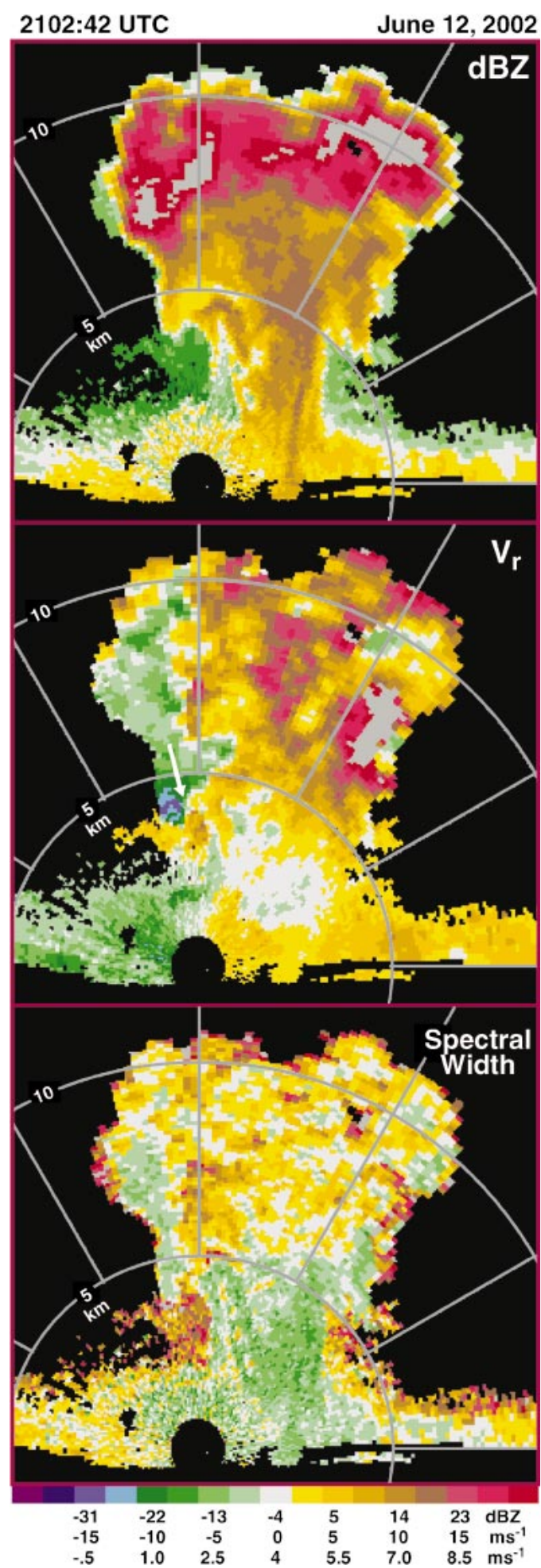

FIG. 12. ELDORA tail radar scan through a developing storm at 2102:42 UTC 12 Jun: (top) radar reflectivity, (middle) single-Doppler velocity, and (bottom) spectral width. A horizontal circulation is indicated by the white arrow on the single-Doppler velocity image. Location of the cross section is shown in Fig. 11. Gray lines are the range rings and angles from the aircraft. storms to become stronger, deeper, and more fully developed prior to the appearance of large echoes aloft or heavy rain at the ground. The latter can be important since the dynamics and evolution of convection can be profoundly different once appreciable precipitation forms.

Some of the alterations were physically motivated while others represented deliberate attempts to compensate for shortcomings inherent in bulk water schemes. The logical first step was to reconsider the cloud-to-rainwater autoconversion process (RAUT). Although based on the legitimate idea that sufficient time and droplet mass are both requirements for raindrop formation, in practice these schemes have no direct information regarding droplet age and thus tend to create the largest number of new raindrops where condensation is most abundant - the main updraft core-making simulation of attendant weak-echo vaults difficult (Tripoli and Cotton 1980). While Straka and Rasmussen (1997) addressed this well-recognized deficiency by directly tracking average particle age in an ice-free model, a practical alternative is to neglect RAUT in favor of cold rain processes, thereby forcing all precipitation to first pass through the frozen stage. ${ }^{2}$ This naturally slows down the precipitation process to some degree, at least when RAUT is excluded. We note that LFO neglected this process as well.

However, excluding cloud-to-rainwater autoconversion was insufficient to slow the rapid buildup of large reflecting particles in the upper portion of the cloud and early and copious hail formation farther below. A striking characteristic of both IHOP cases was how small the reflectivities were given the strength and vertical extent of the cloud circulations. This appeared to be less of a problem with the remaining autoconversion processes than with the accretion rates seeming excessively large, especially those involving lower density ice. Ways of reducing accretion rates were sought that would make a parameterization likely "tuned" for mature convection yield more realistic results for a strong convective storm's early history.

This was addressed in two ways. First, the density of the lower density precipitating ice species was raised to $450 \mathrm{~kg} \mathrm{~m}^{-3}$ from the traditional "snow" value of 100 $\mathrm{kg} \mathrm{m}^{-3}$. Brown and Swann (1997) examined a weakly convective warm-season storm and inferred precipitation-sized ice particle densities to be roughly 500 and $100 \mathrm{~kg} \mathrm{~m}^{-3}$ in the storm's convective and stratiform regions, respectively. Increasing the density for a particle of given mass decreases its cross-sectional area, the single most important factor influencing the accretion rate. Less importantly, the intercept of the lower density ice was reduced to $1 \times 10^{5} \mathrm{~m}^{-4}$ from the more

\footnotetext{
${ }^{2}$ Following Schultz (1995), thresholds for the retained autoconversion processes are expressed as mass contents rather than mixing ratios. This reduces conversion rates in the upper portions of the cloud.
} 


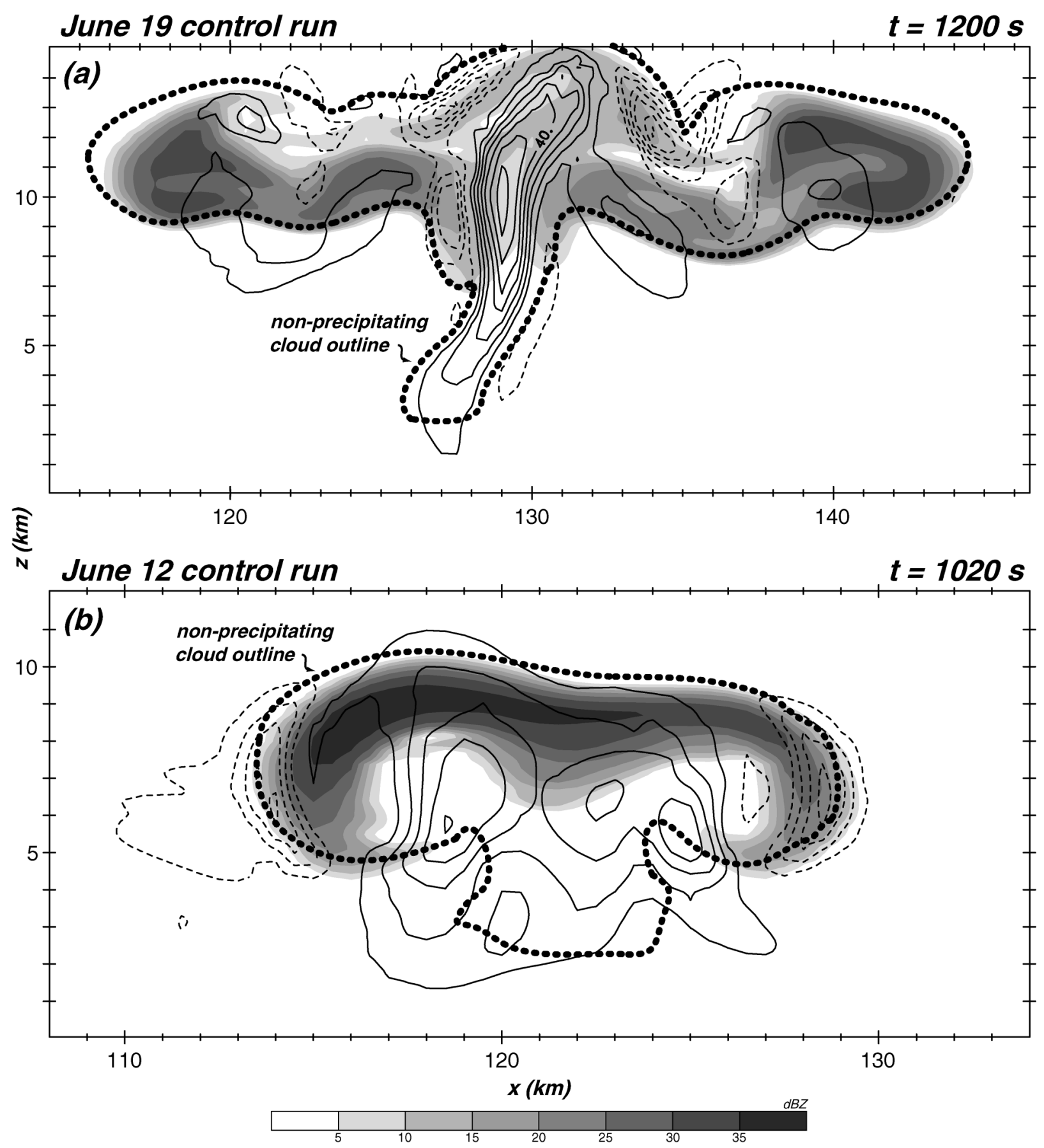

FIG. 13. Instantaneous fields from the 19 and 12 Jun control numerical simulations, showing estimated radar reflectivity (shaded) and vertical velocity [contoured at $8 \mathrm{~m} \mathrm{~s}^{-1}$ in (a), $5 \mathrm{~m} \mathrm{~s}^{-1}$ in (b)]. The $0.5 \mathrm{~g} \mathrm{~kg}^{-1}$ "cloud outline," consisting of nonprecipitating cloud water and ice, is superposed. Only a portion of the domain is shown.

commonly employed $4 \times 10^{6} \mathrm{~m}^{-4}$ value. Decreasing the intercept for a given collector mass content reduces the relative importance of the smaller particles that actually accomplish the largest share of the total accretion. The traditional value appears to stem largely from observations of snowflakes in wintertime, frontal, and/or orographic clouds (e.g., Gunn and Marshall 1958; Ryan
1996) while the intercept adopted herein is more consistent with Musil et al.'s (1976) frozen precipitation samples from newly established cumuli in the famous Raymer storm. It is recognized, however, that size distribution intercepts tend to vary markedly not only among events, but even within a single storm (e.g., Brown and Swann 1997); this motivates examining 

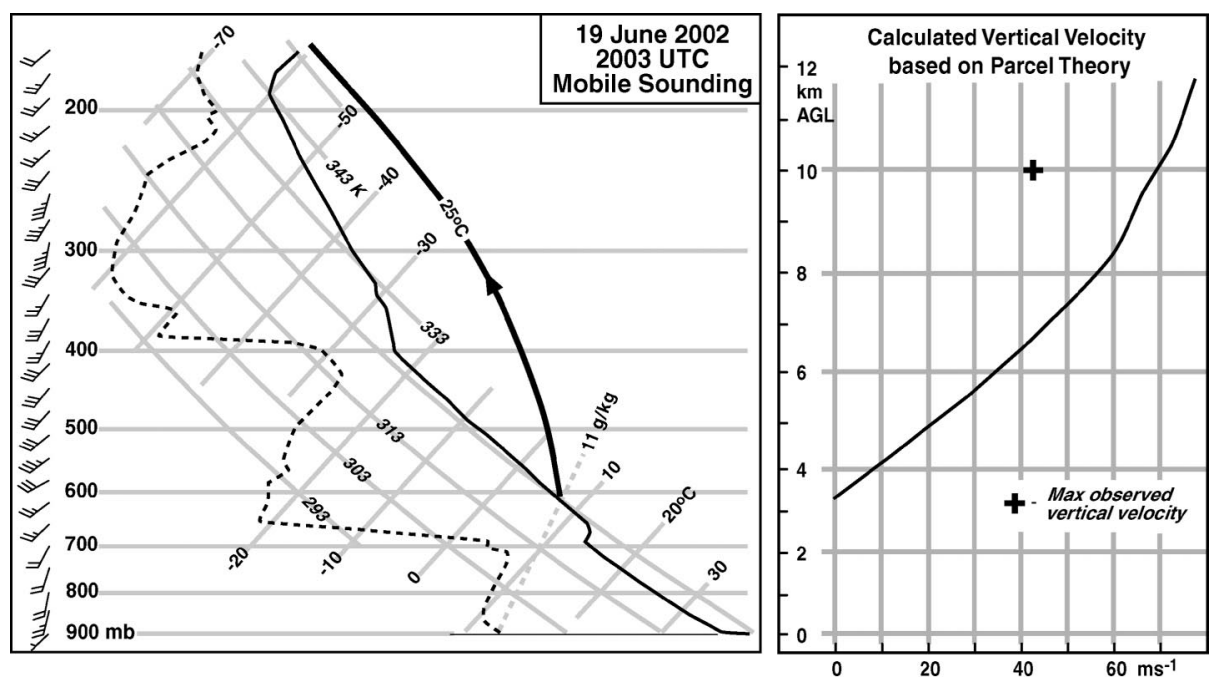

FIG. 14. (left) Temperature (black line) and dewpoint temperature (dashed line) recorded by a rawinsonde launched at 2003 UTC 19 Jun. The location of the sounding is shown by the black circle in Figs. $1 \mathrm{a}$ and 3. The thick black line represents the path a surface parcel would follow. Approximate CAPE value is $3000 \mathrm{~J} \mathrm{~kg}^{-1}$. (right) Calculated updraft velocity derived from parcel theory [(2CAPE) $\left.{ }^{1 / 2}\right]$. Black cross represents the maximum single-Doppler velocities away observed in Fig. 6.

more sophisticated microphysical schemes in the future.

Taken together, these alterations shift the focus of the lower density ice species from large, aggregated snowflakes characteristic of the stratiform region to more compact graupel particles. Alternatively, the changes may be thought of as tantamount to reducing the overall efficiency of the collection process. In any event, two revisions in combination result in a reduction of accretion rates involving lower density ice particles by a factor of 7.

Finally, Bigg's (1953) freezing of cloud droplets was added as an additional source of nonprecipitating ice and, following Cox (1988), the Bergeron processes labeled sinks for cloud water (SFW) and sinks for ice (SFI) were deactivated as redundant. Increasing cloud water transfer rates to nonprecipitating ice further slows precipitation development since accretion processes involving ice crystals are less efficient. The high density precipitating ice (hail) portion of the parameterization was otherwise unaltered though the foregoing changes resulted in slower hail production as well. Significant hail occurred on one of the days (12 June), but not until much later in the storm's life cycle. Simulation results consistent with these observations are reported below.

It will be shown that these modifications in combination dramatically slow the rush to precipitation and provide more realistic simulated echo evolutions in both cases. It should be noted that the microphysical parameterization does not play a primary, driving role in these simulations, even with the default scheme, during the time periods emphasized herein. Even the complete deactivation of precipitation does not significantly alter circulation strength or structure during the thermal as- cent and expansion phases. However, microphysics will eventually play a key role, through the forcing of downdrafts and subcloud cold pools. That time is reached much sooner-and perhaps too soon-when the default microphysical scheme is employed.

\section{b. Initialization}

Figures 14 and 15 present vicinity soundings for the 19 and 12 June events, respectively. Although the two soundings have similarities, the 19 June sounding possesses smaller overall tropospheric stability. Also plotted on these figures is the calculated updraft velocity based on parcel theory. The effect of precipitation loading was not included owing to the weak radar reflectivities observed on these 2 days. The black crosses in Figs. 14 and 15 denote the maximum Doppler velocity recorded in Figs. 6 and 12. There is better agreement between the calculated updrafts and peak Doppler velocities on 12 June (Fig. 15) when compared to values for 19 June (Fig. 14). Recall that the Doppler velocities may underestimate the actual updraft speeds. These plots also may suggest that entrainment of environmental air into the parcel was more vigorous on 19 June.

The highlighted 19 June simulation was made with augmented environmental moisture, with the rationale and consequences discussed below. Both days exhibited a fair amount of vertical wind shear in the lower and middle troposphere, with reversed shear farther aloft, in the horizontal wind component parallel to the radar cross section. That was the $v$ component for the 12 June case, since its cross section was approximately northsouth (Fig. 11).

Unfortunately, the nature and structure of the pertur- 

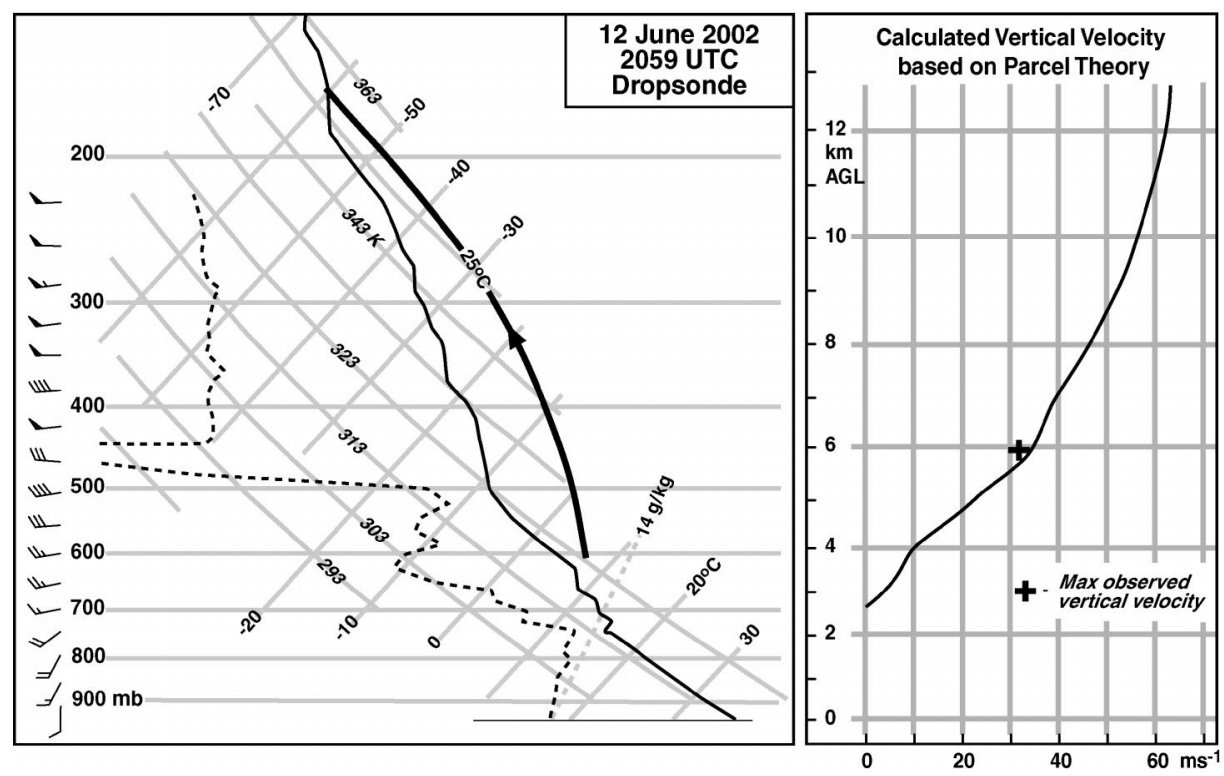

FIG. 15. (left) Temperature (black line) and dewpoint temperature (dashed line) recorded by a dropsonde deployed at 2059 UTC 12 Jun. The location of the sounding is shown by the black circle in Figs. 9a and 10. The thick black line represents the path a surface parcel would follow. Approximate CAPE value is $2030 \mathrm{~J} \mathrm{~kg}^{-1}$. (right) Calculated updraft velocity derived from parcel theory [(2CAPE) $\left.{ }^{1 / 2}\right]$. Black cross represents the maximum single-Doppler velocities away observed in Fig. 12.

bations leading to the 19 and 12 June clouds are not known. Our simulations have employed a conventional cloud model initialization procedure: the introduction of a symmetric, moist thermal into an otherwise horizontally homogeneous environment. However, thermal details were chosen to try to generate results that compared well with the observations. For the highlighted 19 June simulation, the thermal had horizontal and vertical radii of $r_{x}=3.75$ and $r_{z}=3 \mathrm{~km}$, respectively, and was centered at $3.5 \mathrm{~km}$ AGL. Its maximum temperature perturbation was $2 \mathrm{~K}$ and its air was moistened to a relative humidity of $60 \%$ (relative to liquid water). In combination with the sounding's generally low stability, this thermal produced a swiftly ascending cloud that evolved rapidly.

For the 12 June simulation shown, a wider and shallower thermal radius $\left(r_{x}=10\right.$ and $\left.r_{z}=1.5 \mathrm{~km}\right)$ centered at $4.7 \mathrm{~km}$ was used. Though this thermal was made saturated and placed at a higher altitude, it yielded a cloud that was slower in both ascent and evolution. Remarks regarding sensitivity with respect to the initializing thermal and the appropriateness of this kind of convective initiation are given in section $5 \mathrm{~d}$ below.

\section{c. Evolution of 19 and 12 June model storms}

Figure 16 shows updraft and echo structure for the 19 June simulation, at times leading up to that shown in Fig. 13a. As already noted, the narrow and deep thermal promoted the development of a rapidly ascending cloud. First echo appeared around $640 \mathrm{~s}$ after ini- tialization (Fig. 16a), perched atop a strong updraft that was flanked by downdrafts.

The first echo appeared in the rising thermal's cap, where the cloud's oldest surviving cloud and ice particles had time to both accumulate and become small graupel particles. In the next few minutes, the echo grew brighter and started wrapping around the updraft, undoubtedly assisted in doing so by the flanking descent. Maximum updraft strength of $60 \mathrm{~m} \mathrm{~s}^{-1}$ was attained at $t=845 \mathrm{~s}$, shortly before the time of Fig. 16c.

The development of the ram's horns in the simulated echo coincided with general weakening of this initial updraft. By $t=880 \mathrm{~s}$ (Fig. 16c), reflecting particles were becoming concentrated in the updraft's flanking lobes, with reflectivities extending as far down as $7 \mathrm{~km}$ AGL. However, as the updraft weakened somewhat (Figs. 16d and 16e), two wavelike features were spawned, originating on either side of the main updraft. These new updrafts propagated away from the cloud center, their ascent not only helping to keep the precipitating snow particles from falling, but also carrying them higher still. The vertical velocity field suggests the presence of vortical motions involving these updrafts that created and preserved the ram's horns echo feature.

The storm's main updraft started reintensifying from below by around $1040 \mathrm{~s}$ (Fig. 16e). The mechanism of redevelopment was discussed in Fovell and Tan (1998) and relies on the fact that the saturated atmosphere is unstable when equivalent potential temperature $\left(\theta_{e}\right)$ decreases with height. The original updraft represented a ribbon of high- $\theta_{e}$ air drawn upward from the lower tro- 

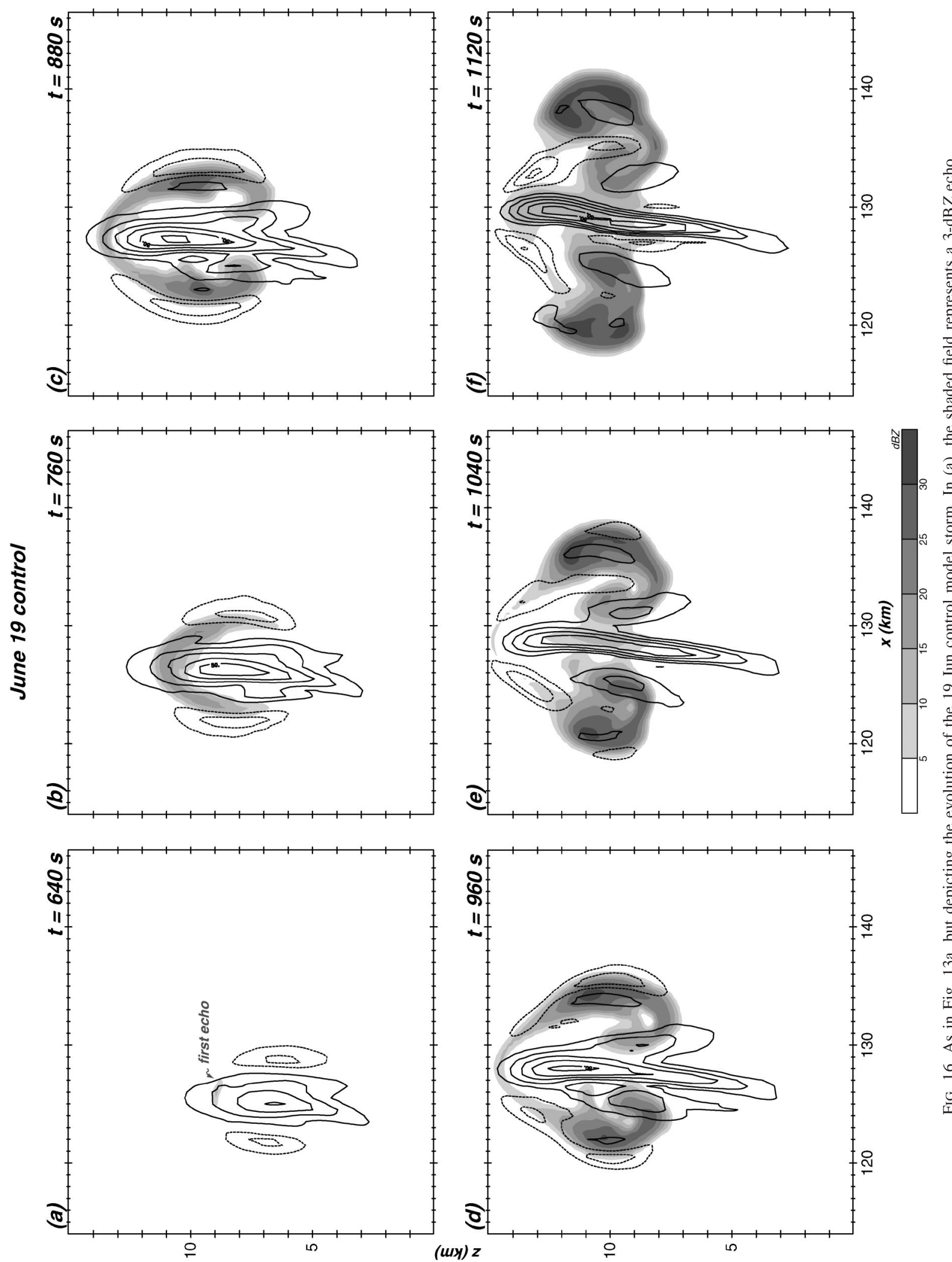
posphere. Entrainment of low- $\theta_{e}$ air at midlevels stabilized the upper portion of the updraft while simultaneously destabilizing the portion of the draft below the entrainment level. Thus, the strong updraft seen in Fig. 13 is essentially a second-generation draft, having followed the same path as its predecessor. It happened that the path was approximately vertical rather than the slanted, as is characteristic of more obviously multicellular storms such as in mature squall lines. The relative discreteness of successive updraft intensifications is somewhat sensitive to start-up conditions but was unattainable without augmented boundary layer moisture.

The cloud acts as a heat and momentum source, both acting to disturb the immediate surroundings. The two wavelike updrafts responsible for creating the ram's horns are most likely internal gravity waves responding to that disturbance. The phase relationship between the two updrafts and the local potential temperature perturbations shown in Fig. 17a is suggestive of gravity waves, despite the complications posed by latent heating. The propagation speeds of the features are not inconsistent with expectations (e.g., Nicholls et al. 1991; Fovell 2002).

The shaded field in Fig. 17b shows where the reflecting particles resided at $t=1200 \mathrm{~s}$ relative to the nonprecipitating water (cloud water and ice) mass, which is contoured. Precipitation at this time was nearly exclusively lower density ice and was concentrated in the cloud's outer and lower peripheries where indeed the oldest condensate would be expected to reside. Owing to graupel's modest fall speed, the reflecting particles remained lofted and became organized by the gravity wave-associated vortical motions at the simulated echo's ram's horns. Farther below, the rotor-associated descent on the cloud's flanks permitted precipitation to descend to about the 8-9-km level, outlining the weakecho vault in the process. Small amounts of hail started appearing in the echo pattern's brighter lobes by about $1000 \mathrm{~s}$ though concentrations never became significant. No reports of hail were received regarding this particular storm cell, although cells that developed subsequently and farther to the north did eventually deliver large hail to the ground. The situation with default microphysical parameterization is very different, as will be seen in section 5e below.

Regarding the 12 June case, vertical motion and reflectivity fields occurring before and after the time shown in Fig. 13b are presented in Fig. 18. The initially induced updraft quickly broadened, developing two local maxima separated by weaker ascent. The first echo appeared in between the two maxima (Fig. 18a) and spread horizontally, forming a slablike crown (Fig. 18b). The two updrafts continued intensifying as they diverged, and flanking downward motion assisted in giving the evolving reflectivity field a pronounced curl (Fig. $18 \mathrm{c}$ ). Eventually, a new updraft maxima appeared between the two original updrafts that quickly became the dominant region of ascent (Fig. 18d). Significant hail accumulations aloft occurred after 960 s, contributing to the rapidly brightening echo pattern; consistent with the observations, a substantial hailfall was produced much later, after the time period of interest. It is encouraging that customized parameterization handled hail well on both days.

\section{d. Influence of the thermal ascent rate and the initial condition}

The 12 and 19 June simulations present strikingly different echo structures and storm evolutions. However, sensitivity testing has revealed that the principal controlling factor is the thermal ascent rate. The 19 June environment itself is somewhat more conducive to permitting the rapid rise of an initial perturbation. However, introducing narrower, deeper, and/or more intense thermals into the 12 June environment yielded qualitatively similar results to those seen in Figs. 13a and 16, including the development of narrower, much stronger updrafts with attendant weak-echo vaults and ram's horns. Similarly, widening and weakening the 19 June thermal generated a model storm that resembled the 12 June structure of Figs. 13b and 18.

This initial condition sensitivity might beg the question of what role thermals play in initializing convection. The classic justification for using thermals, that maturing storms eventually lose "memory" of their start-up mechanism, does not apply when focus shifts to the storm's earliest stages. Indeed, inasmuch as many convective phenomena receive some kind of maintained support from the boundary layer (horizontal convergence, moisture fluxes, etc.), one might wonder why initiating thermals typically extend above the boundary layer, or are even used at all. Perhaps a plume should be employed instead.

However, we are examining the generation of new clouds, and even plumes can be thought of as commencing with "starting plumes" having strong transient resemblances to thermals. Further, many convective phenomena that rely on boundary layer support still evince impulsive and episodic behavior amenable to representation or replacement by a thermal. Two examples are offered. First, the forced lifting accomplished by the propagating cold pool of a mature squall line might appear to represent a persistent, plumelike source of air for the storm. Yet, for a variety of reasons, this inflow commonly becomes systematically punctuated into convective cells. The individual cumulus clouds that grow out of the forced lifting reveal decidedly thermal-like characteristics (e.g., Fovell and Tan 1998, their Figs. 1 and 3). The chief complication here is that each successive bubble is launched in an environment strongly modified by previously generated thermals. In that case, reliance on a possibly unrepresentative proximity sounding is a greater limitation than the treatment of each individual convective cell as a rising thermal. That is less of a concern in the present situation as there was 

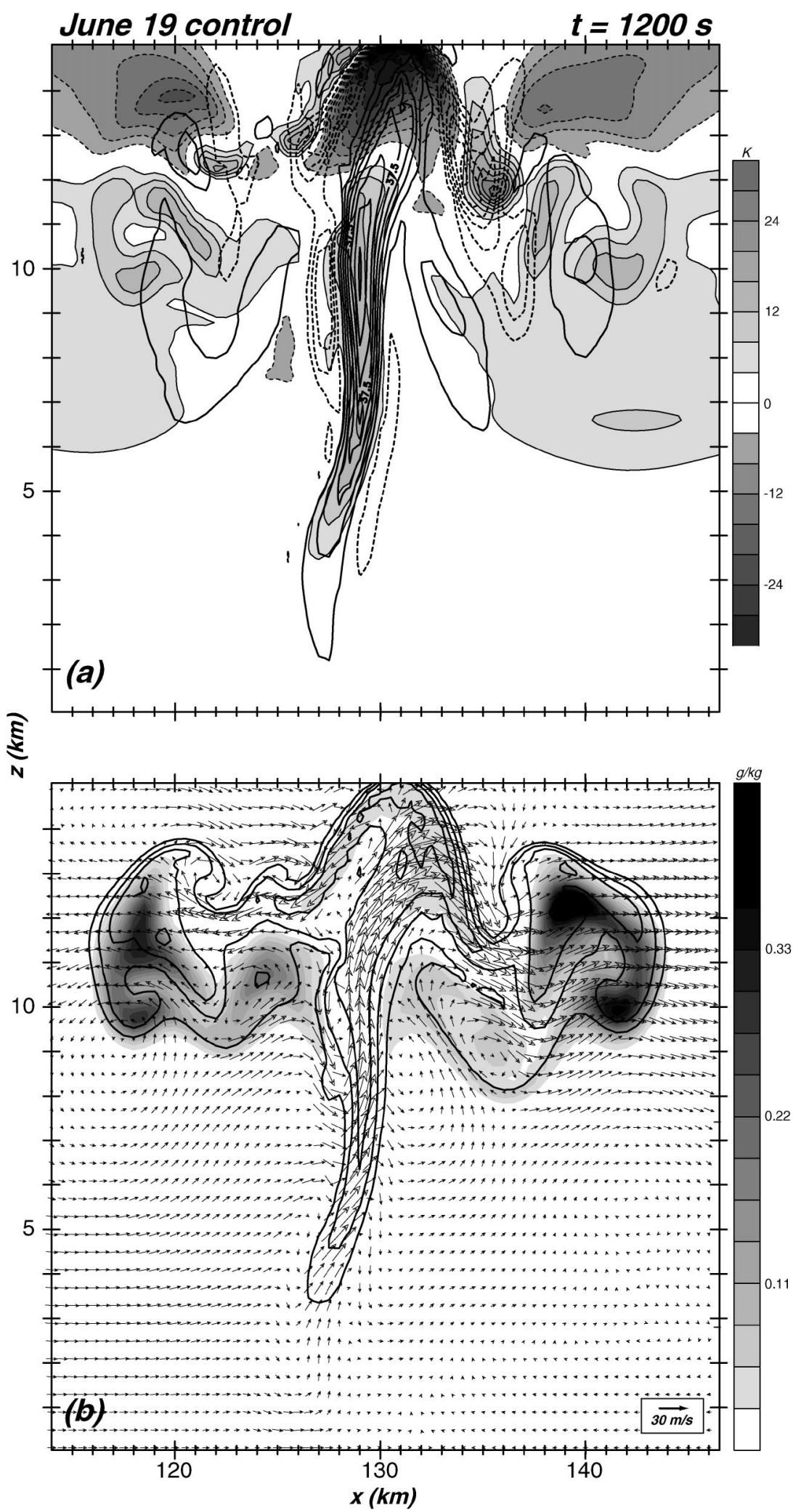

FIG. 17. The 19 Jun control run fields at $t=1200 \mathrm{~s}$ : (a) potential temperature perturbation from the initial state (shaded) and vertical velocity $\left(7.5 \mathrm{~m} \mathrm{~s}^{-1}\right.$ contours) and (b) precipitating ice field (shaded), combined cloud water and nonprecipitating ice field $\left(2.5 \mathrm{~g} \mathrm{~kg}^{-1}\right.$ contours), and ground-relative wind vectors. Only a portion of the domain is shown. 
12 June control run

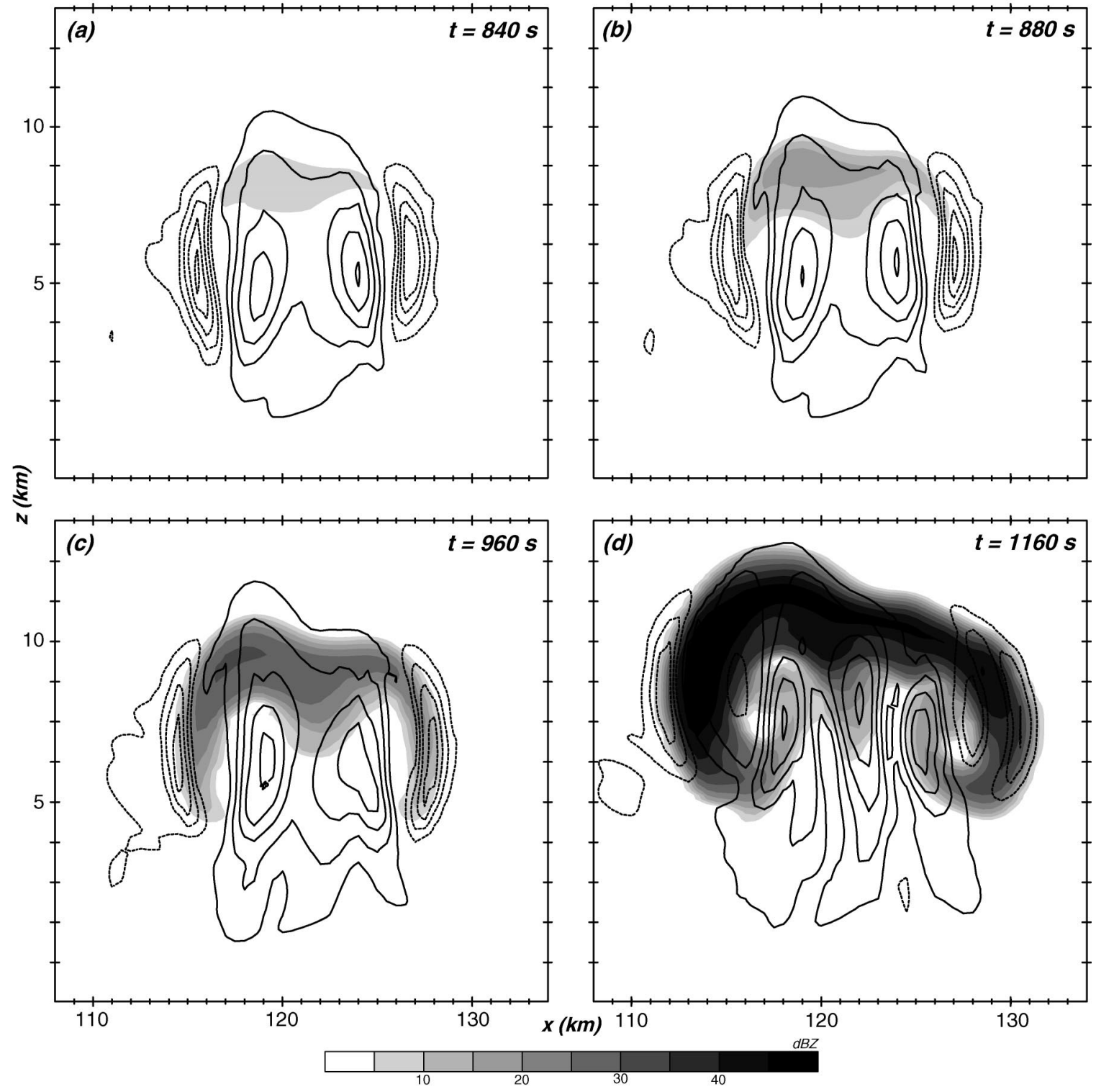

FIG. 18. Evolution of the 12 Jun control model storm, before and after time depicted in Fig. 13b. Vertical velocity contour interval is $5 \mathrm{~m} \mathrm{~s}^{-1}$. In (a), the shaded field represents a $3-\mathrm{dBZ}$ echo.

little existing deep convection when the 12 and 19 June storms under examination fired up.

Thus, an example of likely greater relevance is provided by Fovell and Dailey's (2001) Figs. 2 and 3, which document the effect of deep convection occurring $\sim 10$ $\mathrm{km}$ ahead of an advancing sea-breeze front (SBF). The new cloud appeared in the midtroposphere and exhibited a strong similarity to an isolated rising thermal during its development into deep convection. However, the fact that the cloud resided directly above a boundary layer roll updraft, and subsequently exerted a profound impact on the approaching SBF, might suggest that inclusion of the roll's boundary layer forcing is especially important in this case. Yet, as a shortcut, we can generate a cloud that undergoes a very similar evolution in a seabreeze simulation lacking such rolls by introducing a moist, midtropospheric thermal ahead of the SBF. Like its more naturally forced counterpart, the artificially induced convection establishes a deep, plumelike circulation rooted in the boundary layer and also exerts a qualitatively very similar impact on the SBF, showing that it is the convection itself and not the initial forcing that is of primary importance. Naturally, there is sensitivity to the size, shape, and strength of the initiating thermal, factors that can control the induced cloud's rate of evolution. As in the present study, those factors would have to be selected to be consistent as possible with whatever observations are available. 


\section{June default microphysics}

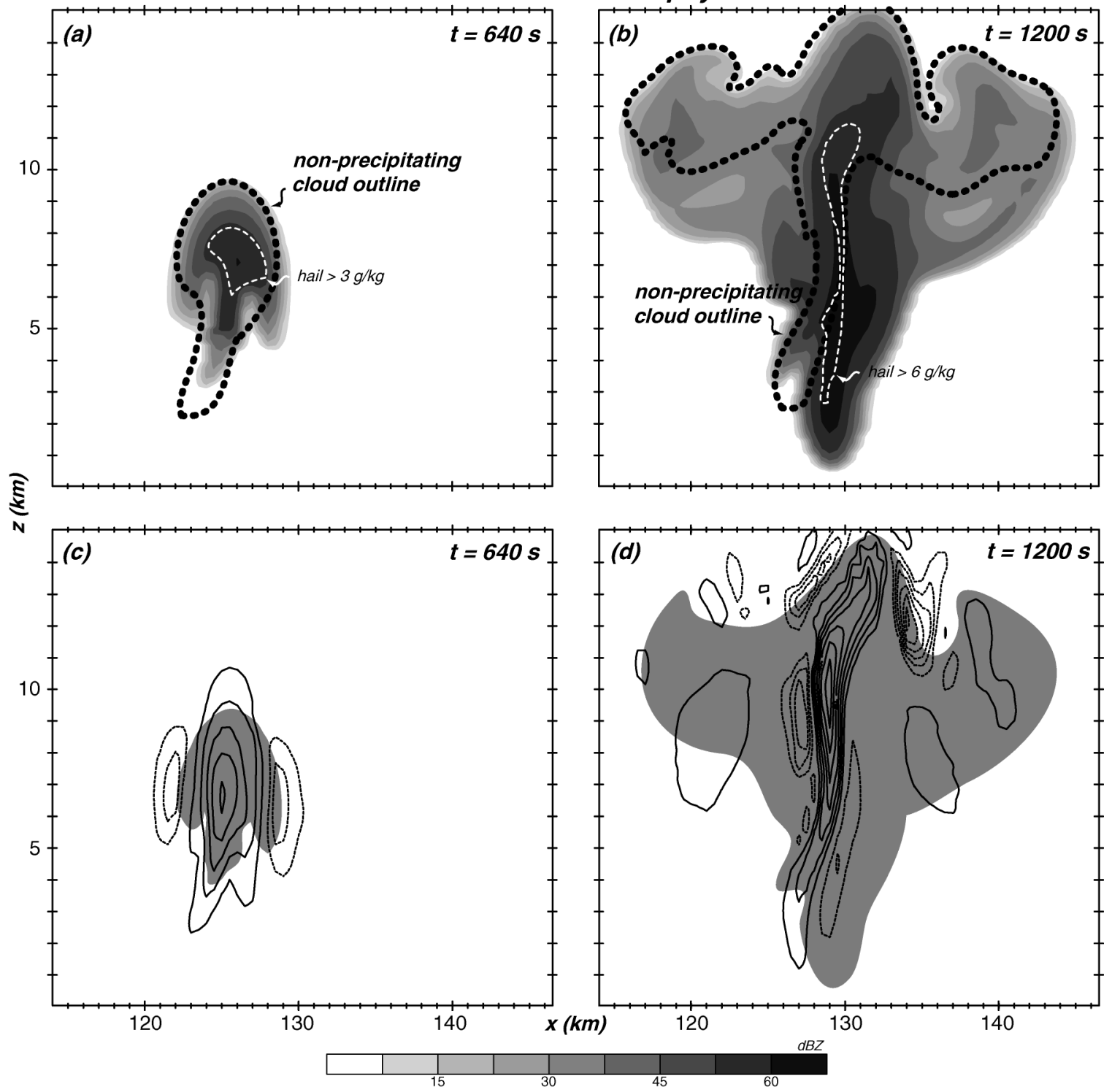

FIG. 19. Instantaneous fields from the 19 Jun simulation with ARPS default microphysics. Again, cloud outline represents $0.5 \mathrm{~g} \mathrm{~kg}^{-1}$ contour of combined cloud water and nonprecipitating ice fields. In (a) and (b), hail mixing ratios (white contours) of 3 and $6 \mathrm{~g} \mathrm{~kg}^{-1}$, respectively, are superposed. In (c) and (d), vertical velocity contour interval is $10 \mathrm{~m} \mathrm{~s}^{-1}$, and shaded field represents extent of the $30-\mathrm{dBZ}$ echo, for reference.

\section{e. The 19 June run with the default microphysical parameterization}

Among the remarkable aspects of the ELDORA observations on both days are the relatively small magnitudes of the radar echoes, the height of their first echoes, and their relatively slow increase in brightness. These aspects have been largely captured in the simulations presented above, but only because of the incorporation of the aforementioned microphysical modifications. For comparison purposes, the 19 June simulation already presented was rerun with standard LFO microphysics. Model fields at $t=640$ and $1200 \mathrm{~s}$ are shown in Fig. 19. It is important to note the characteristics of the initiating thermal were not altered.

The former time saw the appearance of the weak $(\sim 3$ dBZ) first echo in the customized run (Fig. 16a). In contrast, large amounts of swiftly falling precipitation particles had already been created in the default microphysics simulation, resulting in the establishment of an $\sim 60 \mathrm{dBZ}$ maximum echo (Fig. 19a) already containing about $4.5 \mathrm{~g} \mathrm{~kg}^{-1}$ of hail. In the default setup, freefloating cloud and ice is very rapidly scavenged by precipitating ice and rainwater, bringing about a first echo (not shown) that appeared much earlier (at $t=300 \mathrm{~s}$ ) 
and thus at a lower elevation (about $5.6 \mathrm{~km}$ ). The early accumulation of low density precipitating ice permitted prodigious hail development. Despite this, note that the vertical velocity field is not much different between the customized and default microphysics runs, even as late as $t=1200 \mathrm{~s}$ (Figs. 13a and 19d). The timing and elevation of first-echo appearance can easily be modified by adjusting microphysical parameters affecting conversion rates. Naturally, initial thermal characteristics affecting ascent rate are also relevant.

Still, at that time reflectivities exceeding $65 \mathrm{dBZ}$ had already descended below cloud base and were heading for the surface. Once the subcloud cold pool forms, the subsequent dynamical evolution of the storm is markedly affected. As a consequence, the default scheme's "rush to precipitation" carries with it potentially profound dynamical consequences. It should be noted that this precipitation quickening is a characteristic of the microphysical setup and appears largely model independent. The ARPS implementation of the LFO microphysics is fairly standard.

\section{Summary and discussion}

Finescale radar observations of intense thermals/starting plumes, during the early stages of precipitation formation, were collected by an airborne Doppler radar during IHOP on two separate days. The radar data were collected as the aircraft was flying underneath the developing echoes providing a unique view of their vertical structure. A mantle echo (similar to a ram's horns) with a pronounced weak-echo vault was noted on 19 June. The updrafts within the vault were $>40 \mathrm{~m} \mathrm{~s}^{-1}$ based on single-Doppler velocities with downdrafts generally located along the flanks. Numerical simulations using the two-dimensional version of the ARPS model revealed that the horn structure was produced by two gravity waves that were generated on either side of the updraft. The vortical motion created by these waves was critical to replicating the observed echo structure.

The echo structure during the early stages of deep convection on 12 June was similar to a mushroom cloud resulting from a nuclear explosion. The echo possesses a mushroom cap with a narrow trunklike structure below. While large spectral widths were noted within the mantle, the small values within the lower portions of the trunk suggested the flow was more laminar there. Insects were the likely scatterers in the lower portion of the echo while the numerical simulations suggest that hydrometeors dominated the echo aloft. This structure was replicated in the numerical simulations by two distinct updrafts separated by an area of weaker ascent forming a slablike crown in the hydrometeor pattern. Subsequently, a new updraft formed in the latter region.

A remarkable aspect of the observations was relatively small values of radar reflectivity and the height at which echoes first appeared. The numerical simulations were able to replicate these observations only after substantial modifications to the default microphysical scheme used in the ARPS model. Comparison with the vertical structure of the observed echoes on 12 and 19 June suggest that the default setup yields "a rush to precipitation" leading to the early establishment of large precipitation contents. Suggested modifications to the scheme were presented in section 5a. It was shown that the microphysics do not a play a primary role in these simulations, even with the default microphysical scheme, during the early stages of echo formation. Indeed, even a complete deactivation of precipitation does not significantly alter the results. However, microphysics will eventually play a key role via downdraft generation and subsequent cold pool formation, which could have profound influences on the mature stages of the convection.

A limitation of the current study is the lack of temporal continuity of the radar observations. While the vertical structure of the echoes on 12 and 19 June presented in this study are unique, the airborne platform did not resample the same echo until 15-20 min had elapsed. This resolution is too coarse to fully describe the evolution of the echoes. While the numerical simulations are invaluable, future experimental studies should endeavor to increase the temporal resolution.

Acknowledgments. Research results presented in this paper were supported by the National Science Foundation under Grants ATM-0121048 (through RMW) and ATM-0139284 (through RGF).

\section{REFERENCES}

Atlas, D., 1959: Meteorological “angel” echoes. J. Meteor., 16, 611.

Bigg, E. K., 1953: The supercooling of water. Proc. Phys. Soc. London, B66, 688-694.

Bosart, B. L., W.-C. Lee, and R. M. Wakimoto, 2002: Procedures to improve the accuracy of airborne Doppler radar data. J. Atmos. Oceanic Technol., 19, 322-339.

Brown, P. R. A., and H. A. Swann, 1997: Evaluation of key microphysical parameters in three-dimensional cloud-model simulations using aircraft and multiparameter radar. Quart. J. Roy. Meteor. Soc., 123, 2245-2275.

Cotton, W. R., G. J. Tripoli, R. M. Rauber, and E. A. Mulvihill, 1986: Numerical simulation of the effects of varying ice crystal nucleation rates and aggregation processes on orographic snowfall. J. Climate Appl. Meteor., 25, 1658-1680.

Cox, G. P., 1988: Modeling precipitation in frontal rainbands. Quart. J. Roy. Meteor. Soc., 114, 115-127.

Cressman, G. P., 1959: An operational objective analysis scheme. Mon. Wea. Rev., 87, 367-374.

Doviak, R. J., and D. S. Zrnic, 1993: Doppler Radar and Weather Observations. Academic Press, 562 pp.

Fovell, R. G., 2002: Upstream influence of numerically simulated squall-line storms. Quart. J. Roy. Meteor. Soc., 128, 893-912. , and P.-H. Tan, 1998: The temporal behavior of numerically simulated multicell-type storms. Part II: The convective cell life cycle and cell regeneration. Mon. Wea. Rev., 126, 551-577. -, and P. S. Dailey, 2001: Numerical simulation of the interaction between the sea-breeze front and horizontal convective rolls. Part II: Alongshore ambient flow. Mon. Wea. Rev., 129, 2057-2072. 
Gunn, K. L. S., and J. S. Marshall, 1958: The distribution with size of aggregate snowflakes. J. Atmos. Sci., 15, 452-461.

Hall, F. F., J. G. Edinger, and W. D. Neff, 1975: Convective plumes in the planetary boundary layer investigated with an acoustic sounder. J. Appl. Meteor., 14, 513-523.

Hildebrand, P. H., C. A. Walther, C. L. Frush, J. Testud, and F. Baudin, 1994: The ELDORA/ASTRAIA airborne Doppler weather radar: Goals, design, and first field tests. Proc. IEEE, 82, 1873-1890.

Klemp, J. B., R. B. Wilhelmson, and P. S. Ray, 1981: Observed and numerically simulated structure of a mature supercell thunderstorm. J. Atmos. Sci., 38, 1558-1580.

Knight, C. A., and L. J. Miller, 1993: First radar echoes from cumulus clouds. Bull. Amer. Meteor. Soc., 74, 179-188.

_ and _ 1998: Early radar echoes from small, warm cumulus: Bragg and hydrometeor scattering. J. Atmos. Sci., 55, 2974 2992.

Lee, W.-C., P. Dodge, F. D. Marks, and P. H. Hildebrand, 1994: Mapping of airborne Doppler radar data. J. Atmos. Oceanic Technol., $11,572-578$.

Leise, J. A., 1982: A multidimensional scale-telescoped filter and data extension package. NOAA Tech. Memo. ERL WPL-82, 19 pp. [Available from NOAA ERL, 325 Broadway, Boulder, CO 80303.]

Lenschow, D. H., 1970: Airplane measurements of planetary boundary layer structure. J. Appl. Meteor., 9, 874-884.

Lilly, D. K., 1964: Numerical solutions for the shape-preserving twodimensional thermal convection element. J. Atmos. Sci., 21, 8398.

Lin, Y.-L., R. D. Farley, and H. D. Orville, 1983: Bulk parameterization of the snow field in a cloud model. J. Climate Appl. Meteor., 22, 1065-1092.

Malkus, J. S., 1954: Some results of a trade-cumulus cloud investigation. J. Meteor., 11, 220-237.

Marshall, J. S., and W. M. Palmer, 1948: The distribution of raindrops with size. J. Meteor., 5, 165-166.

Mohr, C. G., L. J. Miller, R. L. Vaughn, and H. W. Frank, 1986: The merger of mesoscale datasets into a common Cartesian format for efficient and systematic analysis. J. Atmos. Oceanic Technol., 3, 143-161.

Musil, D. J., E. L. May, P. L. Smith, and W. R. Sand, 1976: Structure of an evolving hailstorm. Part IV: Internal structure from penetrating aircraft. Mon. Wea. Rev., 104, 596-602.

Nicholls, M. E., R. A. Pielke, and W. R. Cotton, 1991: Thermally forced gravity waves in an atmosphere at rest. J. Atmos. Sci., 48, 1869-1884.

Ogura, Y., 1962: Convection of isolated masses of a buoyant fluid: A numerical calculation. J. Atmos. Sci., 19, 492-502.

Oye, R., C. Mueller, and S. Smith, 1995: Software for radar translation, visualization, editing and interpolation. Preprints, 27th
Conf. on Radar Meteorology, Vail, CO, Amer. Meteor. Soc., 359-364.

Reed, R. J., and M. D. Albright, 1997: Frontal structure in the interior of an intense mature ocean cyclone. Wea. Forecasting, 12, 866876.

Reisner, J., R. M. Rasmussen, and R. T. Bruintjes, 1998: Explicit forecasting of supercooled liquid water in winter storms using the MM5 mesoscale model. Quart. J. Roy. Meteor. Soc., 124, $1071-1107$.

Rotunno, R., J. B. Klemp, and M. L. Weisman, 1988: A theory for strong, long-lived squall lines. J. Atmos. Sci., 45, 463-485.

Ryan, B. F., 1996: On the global variation of precipitating layer clouds. Bull. Amer. Meteor. Soc., 77, 53-70.

Schultz, P., 1995: An explicit cloud physics parameterization for operational numerical weather prediction. Mon. Wea. Rev., 123, $3331-3343$.

Scorer, R. S., 1957: Experiments on convection of isolated masses of buoyant fluid. J. Fluid Mech., 2, 583-594.

Smith, P. L., 1984: Equivalent radar reflectivity factors for snow and ice particles. J. Climate Appl. Meteor., 23, 1258-1260.

Straka, J. M., and E. N. Rasmussen, 1997: Toward improving microphysical parameterizations of conversion processes. J. Appl. Meteor., 36, 896-902.

Telford, J. W., and J. Warner, 1962: On the measurement from an aircraft of buoyancy and vertical air velocity in cloud. J. Atmos. Sci., 19, 415-423.

Testud, J., P. H. Hildebrand, and W.-C. Lee, 1995: A procedure to correct airborne Doppler radar data for navigation errors using the echo returned from the earth's surface. J. Atmos. Oceanic Technol., 12, 800-820.

Tripoli, G. J., and W. R. Cotton, 1980: A numerical investigation of several factors contributing to the observed variable intensity of deep convection over South Florida. J. Appl. Meteor., 19, 1037 1063

Turner, J. S., 1973: Buoyancy Effects in Fluids. Cambridge University Press, $368 \mathrm{pp}$

Wakimoto, R. M., W.-C. Lee, H. B. Bluestein, C.-H. Liu, and P. H. Hildebrand, 1996: ELDORA observations during VORTEX 95. Bull. Amer. Meteor. Soc., 77, 1465-1481.

Weckwerth, T. M., and Coauthors, 2004: An overview of the International $\mathrm{H}_{2} \mathrm{O}$ Project (IHOP_2002) and some preliminary highlights. Bull. Amer. Meteor. Soc., 85, 253-277.

Wilson, J. W., and W. E. Schreiber, 1986: Initiation of convective storms at radar-observed boundary-layer convergence lines. Mon. Wea. Rev., 114, 2516-2536.

Xue, M., D.-H. Wang, J.-D. Gao, K. Brewster, and K. K. Droegemeier, 2003: The Advanced Regional Prediction System (ARPS), storm-scale numerical weather prediction and data assimilation. Meteor. Atmos. Phys., 82, 139-170. 